\title{
Review of Power Semiconductor Device Reliability for Power Converters
}

\author{
Bo Wang, Jie Cai, Xiong Du, and Luowei Zhou
}

\begin{abstract}
The investigation shows that power semiconductor devices are the most fragile components of power electronic systems.Improving the reliability of power devices is the basis of a reliable power electronic system, and in recent years, many studies have focused on power device reliability. This paper describes the current state of the art in reliability research for power semiconductor devices, mainly includes failure mechanisms,condition monitoring, lifetime evaluation and active thermal control.Among them,condition monitoring technology are classified and summarized by the failure mechanism and the change rules of characteristic quantities; The method of lifetime estimation isillustrated from the practical point of view; Methods of active thermal control are classified and summarized from the two ideas of reducing loss and loss compensation which are refined by the principle of realization. At last, this paper draws the existing problems and challenges of power devices reliability studies.
\end{abstract}

Index Terms-Active thermal control, condition monitoring, failure mechanism, lifetime evaluation, power device, reliability.

\section{INTRODUCTION}

$\mathrm{P}$ OWER electronic system has high energy conversion efficiency and controllability[1], it has been widely used in aerospace, industrial automation, transportation, renewable energy power generation and other fields which require the highly reliability [2]-[5]. In these fields, the power will fluctuate in a large range [6]-[8], the reliability of power electronic systems with the harsh operating conditions are far less than traditional power equipment. Power semiconductor devices are the core component of power electronic system, and it is also one of the most fragile components in power electronic system [9], so that power device has a significant effect on the reliability of the power electronics system. Thereby, improving the reliability of power devices is one of the focus of power electronics studies. At present, the research on the reliability of power devices mainly includes failure mechanisms, condition monitoring, life estimation and active thermal control etc. As shown in Fig. 1, the study of failure mechanism is the basis of power device reliability research; Condition monitoring and active thermal control

Manuscript received June 10, 2017. This work was supported in part by National Natural Science Foundation of China under Grant 51577020 and 51137006, and in part by Chongqing 2015 Graduate Student Research Innovation Project under Grant CYB15034.

The authors are with the School of Electrical Engineering, Chongqing University, Chongqing, China (e-mail: wbo@cqu.edu.cn; caijie_cee@cqu. edu.cn; duxiong@cqu.edu.cn; zluowei@cqu.edu.cn).

Digital Object Identifier 10.24295/CPSSTPEA.2017.00011 are the implementation means to improve the reliability of power devices; Accelerated aging test and lifetime estimation are the verification methods.

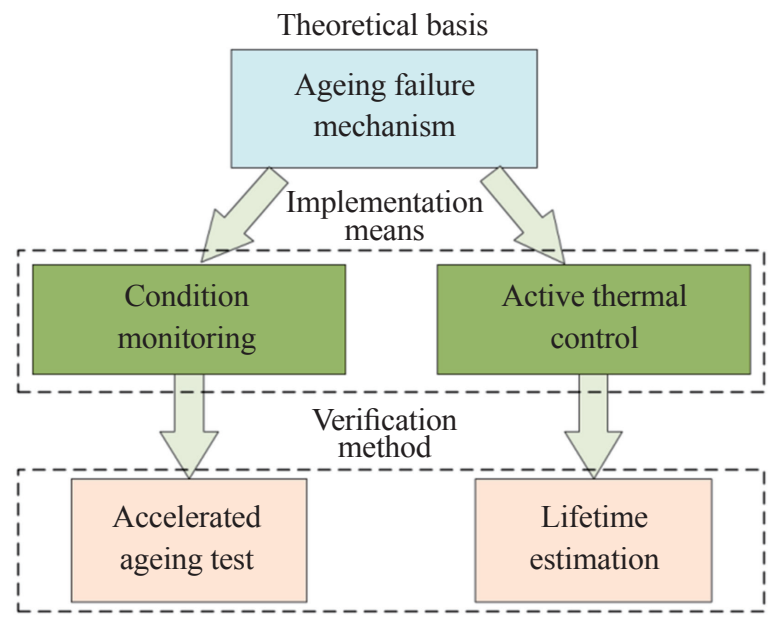

Fig. 1. The main research contents of the reliability of power devices.

Condition monitoring is one of the implementation means to improve the reliability of power devices, it means the health status of power devices is monitored by characteristic quantities in real-time, it enables timely maintenance to prevent the accident shutdown. The studies of condition monitoring are based on the failure mechanism which can be used to find the characteristic quantities and their change rules, and the change rules can beverified by accelerated aging test. Due to Insulated Gate Bipolar Transistor (IGBT) module is the most widely used in power devices, many studies of converter condition monitoring are mainly around IGBT [10]-[12], a great variety characteristic quantities of IGBT are proposed, the results of these studies are discussed in this paper. Active thermal control is another way to improve the reliability of power devices. The main factors causing aging failure of power devices are thermal stresses which are caused by the means temperature and temperature fluctuations.Active thermal control reduces the means temperature or temperature fluctuations by controlling the loss-related variables, thus reducing the thermal stress of power devices.Although the purpose of active thermal control is to improve the power devices lifetime, active thermal control should take account to the costs involved and make a tradeoff between them.Due to the longer service time of power devices, the feedback of active thermal control from the practical application also longer. Therefore, life estimation is generally used to design active thermal control and verify 
the effect of active thermal control. What's more,customers can obtain the lifetime information by lifetime estimation to proper maintenance; manufacturers can make a new design to increase the lifetime of the power devices by lifetime estimation. The method of lifetime estimation is illustrated from the practical point of view in this paper.

In summary, the studies offailure mechanisms, condition monitoring, lifetime estimationand active thermal control have great significance for improving the reliability of power devices. This paper reviews these studies, Section II summarizes the main failure mechanism and failure modes of IGBT modules; Section III summarizes the current condition monitoring method from different point of view; Section IV summarizes the methods of life estimation and the usage method is illustrated; Section V summarizes active thermal control,refines the basic ideas of active thermal control methods and classifies them accordingly; And section VI draws the conclusions and challenges.

\section{Failure Modes and Mechanism of IGBT Modules}

At present, IGBT modules are widely used in high-power occasions. Its relatively low reliability is mainly attributed to its operation feature of dealing with a wide-range random power fluctuations during a long period.Statistics have shown that power converter is one of the most fragile part of the new energy equipment[2]-[5], among them the IGBT modules are also the most fragile part. The failure modes of it can generally be separated into two categories: chip-related failure and packaging-related failure. The chip-related failure can mainly attributed to the catastrophic failures. In the operation of IGBT modules, transient over-voltage, over-current, electrical-over-stress etc. such causal factors could cause catastrophic failures. However, due to their short transient process, these failures are include in the protection category and excluded from the focus of reliability research.

For silicon chip modules, the current research of the reliability research focus more on the package-related failure. The package structure of IGBT module can also be separated into categories: bonding wire structure and press-packaging structure. Between them, the press pack high-power devices, which have a higher reliability than wire-bond devices, are not discussed in this paper.

For the typical multi-layers wire-bond module package device as Fig. 2 shown, when the converter deals with a wide range of random fluctuating power, the power fluctuation causes the power device to withstand the shock of thermal cycle for a long time. The temperature fluctuates repeatedly during the thermal cycle. Due to the differences of mechanical and electrical characteristics of multi-layers, most heat loss transfer vertically downward and the temperature gradient arises from top to bottom within the modules resulting in alternating thermal and electrical stress. The alternating thermal and electrical stress and the bending stress of the bond wire itself, resulting in the crack between the aluminum lead and the silicon chip and gradually spread, and eventually lead to bond wire lift off and solder layer fatigue. Therefore, the IGBT internal temperature fluctuations and the unmatched CTE (thermal expansion coefficient) of different materials leading to alternating thermal and electrical stress, is the root cause of ageing failure. Research shows that the fast power cycling (time period is tens of seconds) and higher temperature swing $(\Delta \mathrm{T}>100 \mathrm{~K})$ leads to wirebond failure, while the slow power cycling (time periodis several minutes) and lower temperature swing $(\Delta \mathrm{T}<80 \mathrm{~K})$ leads to solder fatigue related failures [9].

The failure mechanism of the IGBT modules in the converter mainly includes: bond wire fatigue, aluminum recon-

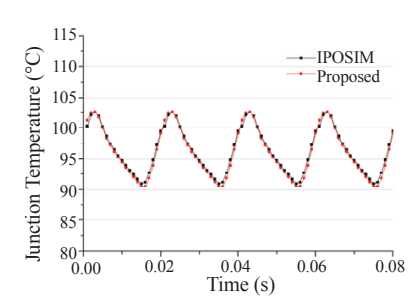

(a) junction temperature fluctuations

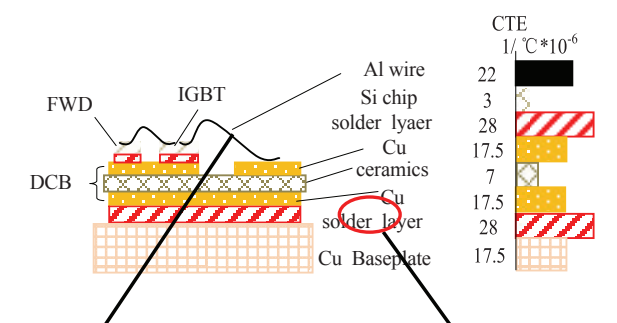

(b) internal structure of IGBT module

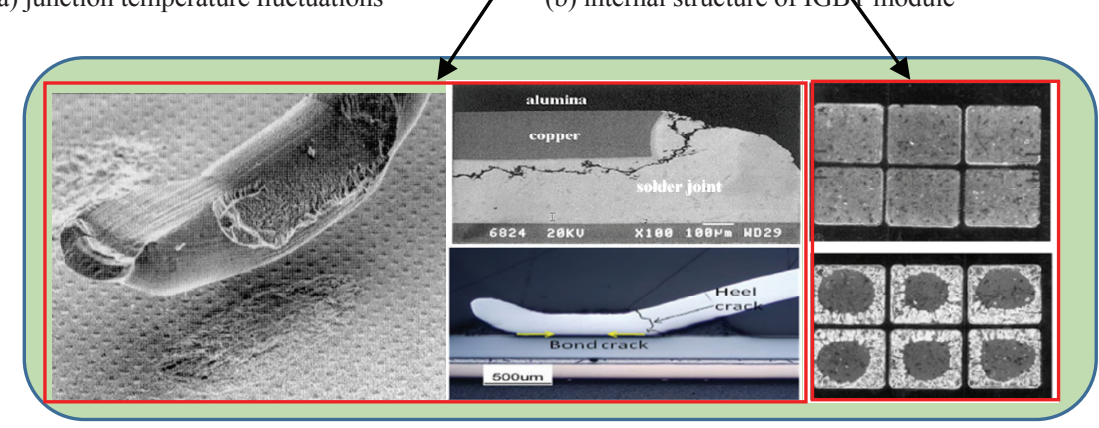

(c) main failure mechanism

Fig. 2. The internal structure of wire-bond package IGBT modules and main failure mechanism. 
struction, solder fatigue and gate oxide degradation [10]. Among them, the aluminum bond fatigue [10], [20] and solder fatigue [21] are the two main failure mechanism of IGBT modules. The aluminum bond wire fatigue including bond wire lift off and heel cracking is caused by the temperature fluctuation and unmatched CTE at the lead-to-chip connection point [12], [22]. The solder layer fatigue refers to the phenomenon of solder cracks and holes under long-term work due to CTE mismatch of the solder connection between the silicon chip and the baseplate [21]. Failures such as solder layer fatigue cracks, cavity and bond wires lifting off or breaking lead to the changes of IGBT thermal, electrical characteristics as well as the degradation of reliability. Thus, failure mechanism is the basis of reliability research of power device.

\section{Condition Montitoring Methods of IGBT MOdULES}

\section{A. General Idea of Condition Monitoring Method}

Condition monitoring of IGBT modules refers to the process of extracting the information reflecting the health status but without interrupting its normal operation simultaneously. In fact, this process can be achieved by monitoring the operating status, and then determine the health level of the device, and finally evaluate the health condition. Thus, systematic maintenance and optimization repair based on condition monitoring can be achieved.

The failure modes of the IGBT modules can be separated into two aspects: sudden failure and aging failure. The sudden failure is instantaneous and unpredictable, belonging to the scope of protection [13]-[15], is not in the discussion of this paper. The ageing failure of IGBT modules are due to long-term work in harsh environment which leading to bear the continuous impact of thermal mechanical stress. Finally, due to the thermal fatigue cumulative damage, the working performance of the module will degrade leading the module parameters or signal shift [16]-[17]. This failure mode is slow and inevitable, if not found in time, will eventually evolve into a catastrophic failure, especially for some high reliability applications will cause incalculable significant losses. Thus, health condition monitoring of the power converter and power devices is of great significance.

At present, a large amount of ageing precursor and monitoring methods has been put forward to monitor the health status of IGBT modules [18]. Some correlation evaluation of these method combined with the practical use is also carried out from serval aspects such as: the intrusion of converter, identification accuracy and on-line application. From the perspective of online application, it can be divided into three parts: on-line monitoring, quasi-on-line monitoring and offline monitoring. It can also be divided into classical ageingprecursor, new ageing precursor, global variable and other precurso raccording to its different characteristics. However, few literatures indicate the general idea of converter condi- tion monitoring. Based on the existing research, this paper concludes the general idea of condition monitoring method of IGBT modules. The basic idea is shown in Fig. 3.

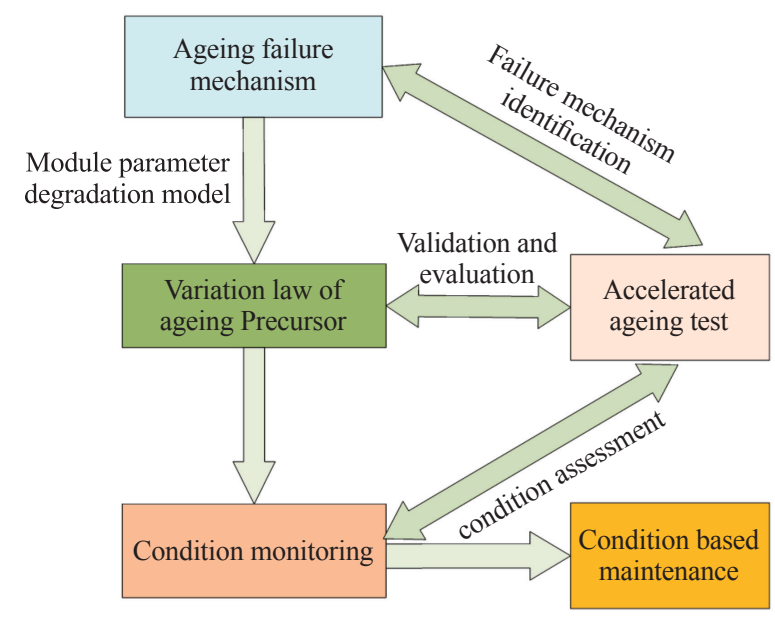

Fig. 3. General idea of condition monitoring.

From Fig. 3, the condition monitoring of the IGBT modules can be divided into three steps: the aging failure mechanism, the change characteristic of ageing precursor and the realization of the condition monitoring. The general idea can be described as follows:

1) Making a deep analysis of the aging failure mechanism and conducting the accelerated aging test based on the operating conditions and fatigue theory;

2) Modeling the IGBT module considering the degradation of parasitic parameters in the aging process and determining whether the feature can reflect the health condition and its changing trend based on the failure mechanism of IGBT module;

3) Verifying the changing characteristics of the module and making a comprehensive evaluation through the accelerated aging test;

4) Finally, based on a large number of aging test data, determine the certain correspondence between the precursor and the aging level of the device, determine the evaluation index of the health status of the module and finally use it for the health monitoring of the module.

Among them, the failure mechanism is the basis for the realization of converter condition monitoring. Accelerated aging test is an important means to reveal the physical failure mechanism and characteristic variation of the module, and the condition monitoring is the final means based on the terminal characteristics of the converter and power device. These three aspects will be described in detail below.

\section{B. Condition Monitoring Indicators of IGBT Module}

The health status of the IGBT module is closely related to its terminal characteristics. With the increase of power cycling of IGBT module, the thermal stress caused by the CTE mismatch will lead to the bond wire fatigue and the solder fatigue. The two main different failure mechanism will lead 
to some changes in its terminal electro thermal characteristics, providing the reference and basisfor the IGBT condition monitoring. The key of IGBT health monitoring is to find the ageing precursor that reflects the health condition of IGBT module.With the aging process, the most significant change in the terminal characteristic is the increase in the on-state voltage drop and the thermal resistance. In order to analyze the variation rule of the terminal characteristic, the equivalent circuit model considering the packaging parameters are shown in Fig. 4, where $R_{\mathrm{EW}}$ and $L_{\mathrm{EW}}$ are the parasitic resistance and inductance of the bond wire respectively. $R_{\mathrm{GW}}$ and $L_{\mathrm{GW}}$ are the gate parasitic resistance and inductance respectively. $C_{\mathrm{GC}}$ and $C_{\mathrm{GE}}$ are parasitic capacitance. The aging of the module will lead the change of the bond wire parasitic parameters and gate parasitic parameters, resulting in the change of its terminal electrical characteristics.

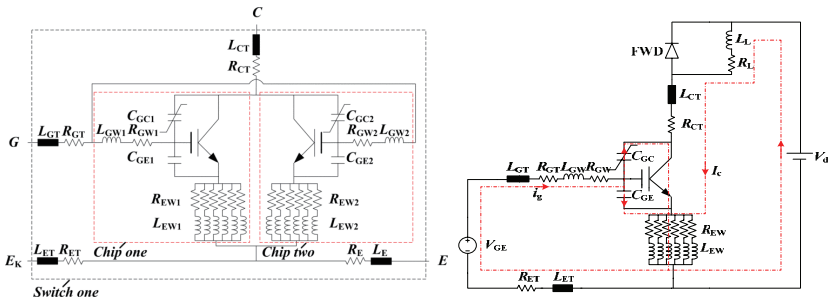

Fig. 4. The equivalent circuit model considering the ageing parasitic parameters.

$$
\begin{aligned}
& I_{\mathrm{SC}}=\frac{\mu_{\mathrm{ni}}\left(T_{\mathrm{j}}\right) C_{\mathrm{OX}} z}{2 L_{\mathrm{CH}}\left(1-\alpha_{\mathrm{PNP}}\left(T_{\mathrm{j}}\right)\right)}\left(V_{\mathrm{G}}-R_{\mathrm{EW}} I_{\mathrm{SC}}-V_{\mathrm{TH}}\left(T_{\mathrm{j}}\right)\right)^{2} \\
& V_{c e_{-} \text {sat }}=V_{c e_{-} 0}\left(T_{\mathrm{j}}\right)+I_{\mathrm{C}} R_{\mathrm{EW}} \\
& \Delta V_{G E}=L_{E W} \frac{d I_{C}}{d t}+I_{\mathrm{C}} R_{\mathrm{EW}}
\end{aligned}
$$

Through the equivalent circuit model shown in Fig. 4, we can get some simple expression of partial ageing precursor (short circuit current $I_{\mathrm{SC}}$, saturation voltage drop $V_{\text {cesat }}$ and gate voltage change $\Delta V_{\mathrm{GE}}$ ) shown in the (1). It can be seen from the formula that the aging of the module will have an impact on the change of bond wire parameters which leading to the change of these precursors. Meanwhile, the aging of the solder layer will lead to the increase of the equivalent thermal resistance and the degradation of heat dissipation performance. Moreover, the increased thermal resistance also lead to the increased junction temperature $\left(T_{\mathrm{j}}\right)$ and thus affect the external characteristics of the module.Therefore, the aging of the solder layer not only leads to the increase of the thermal resistance directly but also leads to the increase of the junction temperature and the changing of the external electro-thermal properties in a certain degree. So it's significant to identify the variation law of the ageing precursor.

However, due to the complex packaging structure and physical structure of IGBT modules, it's hard to model the IGBT consider the ageing degradation parameters correctly and comprehensively. From the above partial precursors' for- mula and equivalent circuit, it can be seen that the precursors are often affected by multi-factors and have the characteristics of nonlinearity and strong coupling effects. Therefore,It is difficult to reveal its specific change rule and determine the certain failure level by direct theoretical analysis, but it is useful to identify whether the precursor are affected by ageing failure and its changing trend. Thus, after the simple theoretical analysis, it is still necessary to further evaluate the changing trends and validate the failure level through the accelerated aging test.

At present, a large amount of studies has been carried out on the characteristics of IGBT modules. The theoretical analysis and experimental results show that the saturation voltage drop $\left(V_{\text {ce sat }}\right)$, threshold voltage $\left(V_{\text {th }}\right)$, transconductance $\left(K_{\mathrm{p}}\right)$, short circuit current $\left(I_{\mathrm{SC}}\right), I-V$ characteristics, switch transient signal $\left(t_{\mathrm{on}}, t_{\mathrm{off}}, V_{\mathrm{GE}}\right)$, gate parasitic parameters, case temperature $\left(T_{\mathrm{c}}\right)$, junction temperature $\left(T_{\mathrm{j}}\right)$ et al. can all be used as the indicators [12], [18], [22]. Part of the variation law of the ageing precursor with the ageing process is shown in Fig. 5.

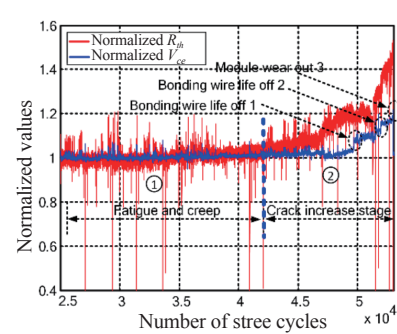

(a) Rth and Vce

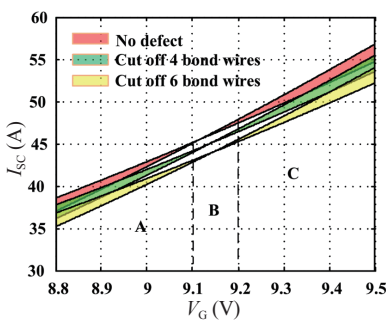

(c) $I_{\mathrm{sc}}$

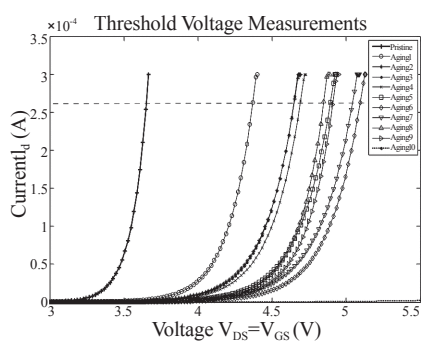

(b) Vth

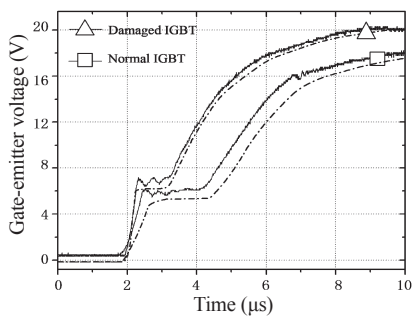

(d) $V_{\mathrm{GE}}$
Fig. 5. Partial ageing precursors and it's variation law [23]-[26].

\section{Analysis of Condition Monitoring Method of IGBT Mod- ule}

As discussed above, different failure mechanism of IGBT module will lead to some changes in its terminal characteristics.Among them, the aging of the bonding wire will lead to changes in the electrical parasitic parameters within the module, the terminal electricalcharacteristics changes can be separated into two categories: steady characteristics and transient characteristics.Besides, the aging of the solder layer will mainly leads to the significant change of the thermal resistance and thermal characteristic of the module. These two categories will be described below separately.

\section{1) Condition Monitoring of Bond Wire Fatigue}

Because the bond wire is enclosed in the IGBT module, it 
is difficult to observe its variation. In addition, the bond wire related parameters are extremely small, making it difficult to measure. Therefore, the study of aging failure of the bonding wire is still difficult. At present, the health status monitoring of IGBT module based on the bond wire fatigue can be mainly divided into two aspects: steady-state monitoring and transient monitoring. The steady-state characteristic quantity mainly includes $V_{\text {ce sat }}[23]$, [30], $V_{\text {th }}, K_{\mathrm{p}}, I_{\mathrm{SC}}$ [25], $R_{\text {on }}$ et al. [18], and the transient electrical characteristic mainly includes switching transient time $\left(t_{\text {on }}, t_{\text {off }}\right)$ [12], [18], gate voltage current variation [26], [27] and so on.

In the field of steady-state condition monitoring, most research currently use $V_{\text {ce sat }}$ of IGBT module to achieve online monitoring [28], [29]. The $V_{\text {ce sat }}$ of the IGBT module increases with the aging process, so the health level of the IGBT can be monitored by monitoring the saturation voltage drop [6], [31]-[35]. However, $V_{\text {ce_sat }}$ is nonlinear with the collector current $I_{\mathrm{c}}$ and the junction temperature. Therefore, it is necessary to test the IGBT module under specific conditions, which increases the difficulty of on-line application. Meanwhile, the variation of $V_{\text {ce }}$ caused by ageing effects is generally only tens of millivolts, but the bus voltage is up to 100 volts or even kilovolt, which needs higher requirement of measurement equipment.Choi et al.[32], [33] proposes an on-line measurement method of the $V_{\text {ce_sat }}$, and the saturation voltage drop near the inflection point in the output characteristic curves is not affected by the junction temperature(shown in the Fig. 6)[34], [35]. Therefore, the $V_{\text {ce sat }}$ near the inflection point measured at a specific current can accurately achieve bonding wire health monitoring, the $V_{\text {ce sat }}$ online measurement circuit and identification results are shown in Fig. 6.

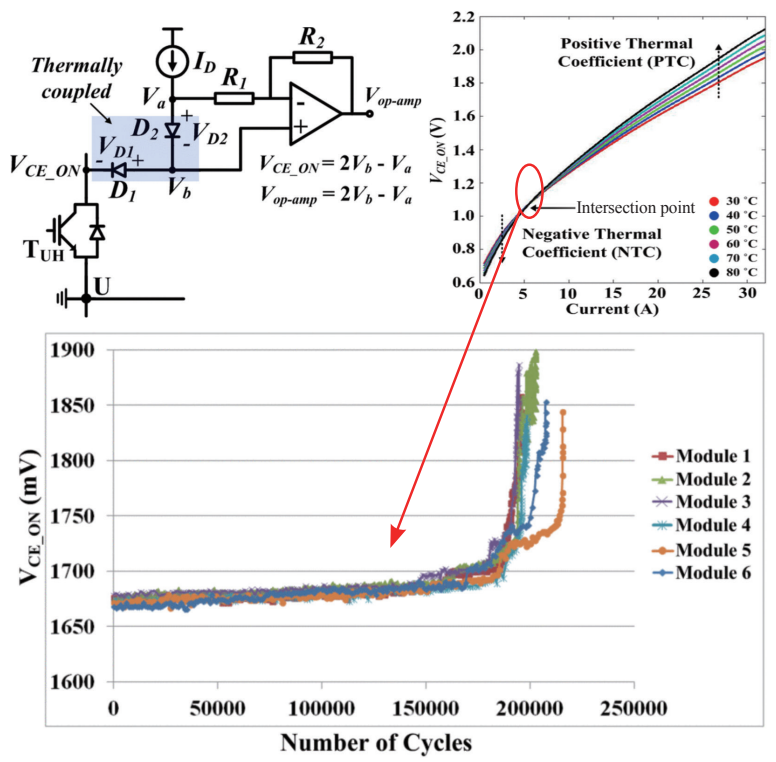

Fig. 6. On line Vce measurement circuit and Vce monitoring results at the infection point [34].

In the same way, Sun et al. [25], [36] propose the short-circuit current can be used as a precursor of the IGBT modules.
The theoretical analysis and the experimental results shows that the short-circuit current near the inflection point of the transmission characteristic curves is not affected by junction temperature, bus voltage and complex working conditions. Thus, the short-circuit current under the specific driver voltage can directly reflect the health condition of IGBT module. The corresponding experimental resultsare shown in Fig. 7.

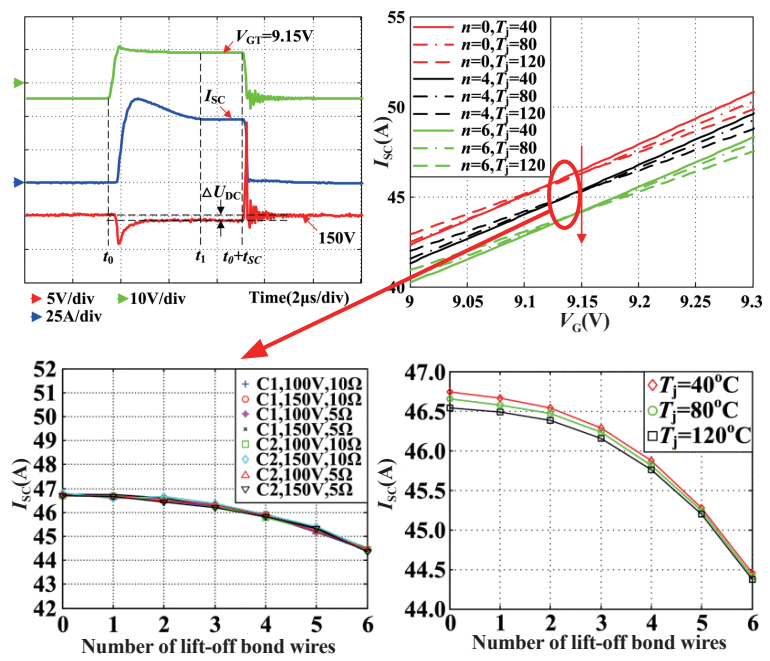

Fig. 7. Short circuit current measurement waveform and measurement results under different condition [36].

The two steady state monitoring method under specific measurement condition discussed above can both avoid the coupling influence of junction temperature and other parameters can reflect the health status of the bond wire well. Besides, the transconductance and threshold voltage of the IGBT module also change with the aging of the module [24], [37], [38], and the transconductance-based condition monitoring method is difficult to achieve on-line application due to the limitations of its specific measurement requirement. The monitoring method based on threshold voltage is divided into two types: static threshold voltage and dynamic threshold voltage [39], [40]. The static threshold voltage measurement requires the converter to be in the shutdown state, it is also difficult to achieve on-line measurement. The dynamic threshold voltage measurement needs to detect sudden change moment of $I_{\mathrm{c}}$ and $V_{\mathrm{ce}}$, the measuring process can easily be affected by the noise factors. Besides, these two parameters are both affected by temperature, so the effect of junction temperature could not be ignored.

The condition monitoring of the IGBT module based on the transient characteristic is mainly based on the gate voltage or current signal, the gate parasitic parameter, the switching transient time and so on. Du and Zhou et al. [26], [27], [41] investigate the relationship between the gate signal and the health level of IGBT module. The relationship between the change of the gate signal and the aging state of the module is shown in Fig. 8. The study shows that the gate signal shows little difference unless a chip is damaged or all the bond wire on the chip lifting off in the multi-chip paralleled modules. Therefore, accurate identification of the 
bond wire based on the gate signal could not be achieved, the identification accuracy is low.

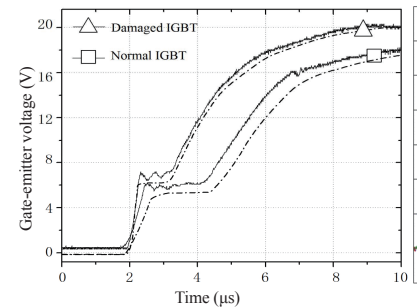

(a)

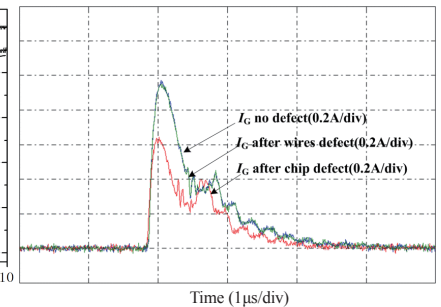

(b)
Fig. 8. The varies of gate signal at bond wire liftoff station [26], [27].

The switching transient time of the power device also changes with the aging of the power device [12], [18], [42], Brown et al. [43] proposed turn-off time $\left(t_{\text {off }}\right)$ can effectively reflect the power device condition due to latching effect caused by ageing, the experimental results are shown in Fig. 9. Condition monitoring based on the switching transient time needs higher requirements for the measuring equipment, and it is easy to be affected by the complex factors such as junction temperature and complex working condition, the practical application is difficult.Besides, the condition monitoring based on the main circuit switching precursor is more invasive to the normal operation of the converter.

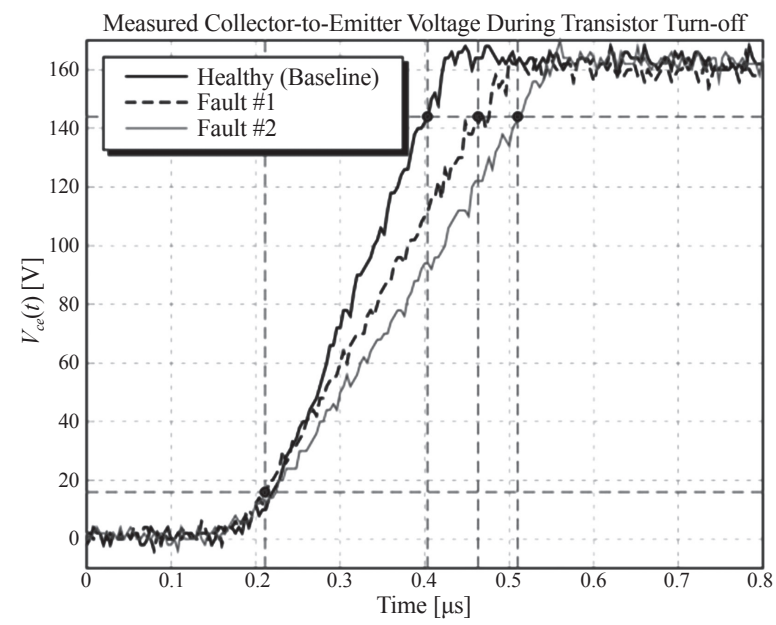

Fig. 9. Collector-Emitter voltage waveform before and after IGBT aging [43].

\section{2) Condition Monitoring of Solder Layer Fatigue}

The aging of the solder layer leads to the degradation of the module's thermal performance, directly causes the increase in the thermal resistance of the IGBT module, result in abnormal changes in the junction temperature and case temperature of the IGBT modules [44], [45]. So the thermal resistance, junction temperature, case temperature can be used as monitoring indicators.

The type of thermal resistance monitoring is generally divided into static thermal resistance and dynamic thermal resistance, the two measurements are basically the same. Generally, the static thermal resistance increases by $20 \%$ rel- ative to the initial value is regarded as the failure criteria of IGB modules [46], and the dynamic thermal resistance curve will drifts after aging [47]. Therefore, monitoring of IGBT module thermal resistance can determine the health state of the IGBT module. Ji et al. [48] present an on board method to test the thermal resistance of IGBT module in off-line condition. The method requires the addition of measurement program and measuring equipment to realize the extraction of thermal impedance parameters after the converters completely shut down. Du. X et al. [49] propose a quasi-on-line thermal network parameter identification method of IGBT module based on the cooling curve of junction temperature. This method does not require additional heating current source, the measuring process can be conducted in the process of converter shut down without intrusion of the converter normal operation.

The junction temperature can also be used as an indicator for condition monitoring [10], [18]. However, due to encapsulation of IGBT module, it is difficult to achieve a direct measurement of junction temperature without modifying the package. On the other hand, indirect measurement of the junction temperature is possible. The junction temperature can be extracted through the terminal thermo-sensitive electrical parameters. Part of the typical thermo-sensitive electrical parameters are shown in TABLE I.

TABLE I

Junction Temperature Sensitive Parameters

\begin{tabular}{cc}
\hline \hline Parameter & Definition \\
\hline $\mathrm{t}_{\text {diff }}[50],[51]$ & Miller platform time \\
$\mathrm{V}_{\mathrm{eE}}[52],[53]$ & voltage between the main emitter and the auxiliary emitter \\
$\mathrm{V}_{\text {ce.on }}[36]$ & saturation voltage \\
$\mathrm{V}_{\text {ge.th }}[40]$ & threshold voltage \\
\hline \hline
\end{tabular}

Rodriguez-Blanco and Sundaramoorthy et al. [50], [51] point out that the Miller platform delay can be used as the characteristic of the junction temperature measurement, and the temperature sensitivity is $1.1 \mathrm{~ns} /{ }^{\circ} \mathrm{C}-3.5 \mathrm{~ns} /{ }^{\circ} \mathrm{C}$. Luo et al. [52], [53] propose that the amplitude and turn-off delay time of the voltage $V_{\mathrm{Ee}}$ induced by the parasitic inductance between the main emitter and the auxiliary emitter of the IGBT module can also be taken as the characteristic of the junction temperature estimation of the IGBT module.

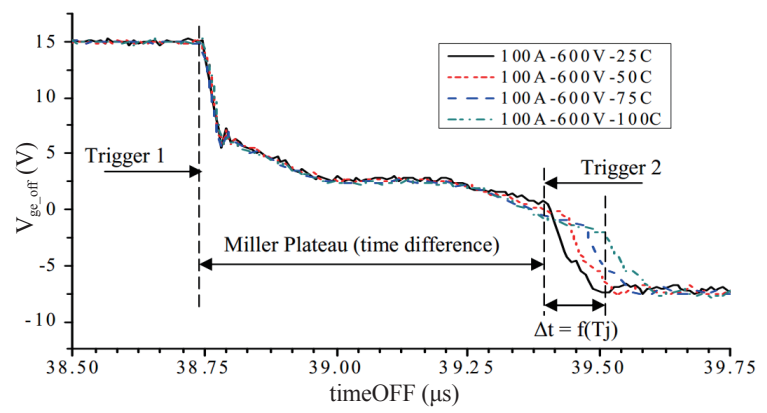

Fig. 10. Gate voltage turn-off signals at different temperatures [51]. 


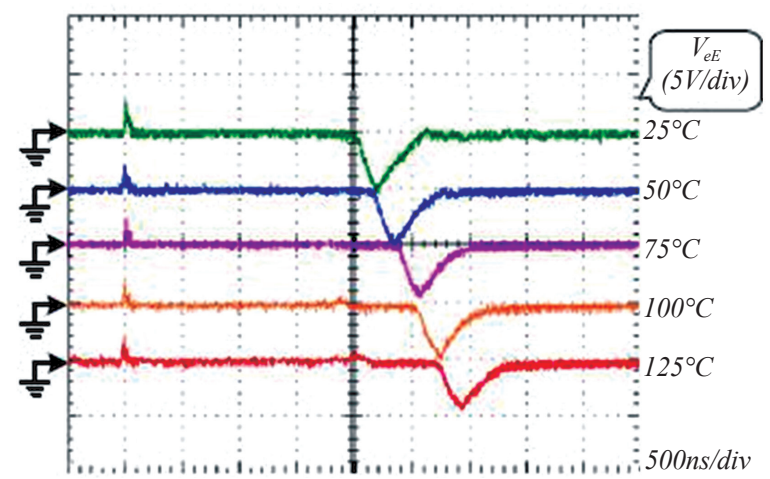

Fig. 11. VeE waveform at different temperature [52].

The case temperature can also reflect the health condition and junction temperature after dexterously treatment [54][56]. The change of the case temperature can reflect the aging state of the device [54], it's temperature distribution of at different location can both reflect the bond wire fatigue and solder layer fatigue of the device [55]. Besides, the mean values of the different chip case temperatures in the same module can be used to estimate junction temperature [56].

Finally, it is worth noting that the ageing parameters of the IGBT module are often affected by the coupling of multiple factors. Generally, almost all the precursor are affected by the junction temperature. In the actual converter operation, the solder layer of the aging will lead to abnormal changes in junction temperature, which has a significant effect on the bond wire monitoring parameters. At the same time, the aging of the bonding wire, aluminum reconstruction and other failure mechanism, will lead to increased loss of the module and thus lead to junction temperature and case temperature changes. Therefore, there are strong coupling effects among mutli-indicators. It is still unrealistic to rely on a single ageing precursor to realize the condition monitoring of the IGBT module and even the whole converter. Besides, how to avoid the influence of other factors when using the condition monitoring parameters and find characteristics that can reflect health condition of IGBT module more comprehensively is still of great importance. It is also the focus of future research to realize the more comprehensive monitoring of the health status of from the power device to the converter based a large amount of test data analysis and data fusion from actual converter operation.

\section{LifETIME Estimation}

Junction temperature fluctuation is the main factor leads to power device failure, according to the failure mechanism. In the actual conditions of the junction temperature fluctuations can generally be divided into long, medium and short time scales. Among them, the long time scale means ambient changes which are slow changes; the medium time scale means low frequency junction temperature fluctuations caused by input and output power fluctuations of converters, such as random variation of wind speed in the wind power converter; the short time scale means fundamental frequen- cy junction temperature fluctuations followed by the output frequency of converter. All of the junction temperature fluctuations at different time scales will consume the life of the power device, and the lifetime expectancy of the power device should be considered for multiple-time scales [57]. Usually the power device manufacturers provides the lifetime expectancy only under a single thermal load condition in the application manual[58], [59]. So the lifetime expectancy of power device in the actual conditions can not be obtained directly from the application manual, it is necessary to be estimated by lifetime estimation technique.

Customers and manufacturers of power devices want to estimate the lifetime of power devices under certain operating conditions. On the one hand, customers hope lifetime estimation can help to reduce the expense of conservative maintenance. On the other hand, lifetime estimation can also help manufacturers to design new devices, which can have a longer service life.What's more, life estimation is generally used to design active thermal control and verify the effect of active thermal control. This section reviews the present situation of lifetime estimation.

\section{A. Junction Temperature Evaluation}

The junction temperature evaluation is the fundamental of lifetime estimation of power devices. The methods of junction temperature evaluation are mainly classified into two categories: the junction temperature measurement and the junction temperature estimation. The junction temperature measurement is divided into direct measurement method and indirect measurement method, in which optical method and physical contact method belong to direct measurement, and thermo-sensitive electrical parameters(TSEP) belongs to indirect measurement. The optical method is non-contact,which measures the chip temperature of opened module by Infrared Radiation camera (IR) [60]; physical contact requires the installation of temperature sensors on chip surfaces, such as the thermocouple or the fiber [61]. These two methods are generally used in labs. The TSEP such as saturation voltage, gate voltage, threshold voltage, short circuit current, etc. can be used to monitor the junction temperature [62]-[67]. It can be applied online, but there are still some issues such as accuracy, expensive, vulnerable to interference, so that it has not ready to wide application.

At present, the most widely used method of online junction temperature evaluation is the junction temperature estimation based on the thermal network [68]-[74].This method is implemented by two steps, firstly, the loss of power devices is calculated according to the operating conditions, and then the junction temperature is calculated by the case temperature and the thermal network. The thermal network parameters can be extracted by finite element method, analytic model method, extended description function method, polynomial fitting, equivalent RC thermal network etc. [75]-[77]. The accuracy of the estimation is mainly limited by accuracy of the loss calculation. In addition, the thermal network parameters will change with power devices ageing, it also has 
a great influence on the accuracy of junction temperature estimation [78]. Some other methods for junction temperature estimation have been reported.The temperature field distribution of the chip is calculated by the finite element modeling method [79]; in [80], the transient junction temperature is calculated by Fourier series; literature [81] uses finite difference method to solve the 3-D heat distribution of devices etc. The above three methods are only suitable for simulations and are not suitable for the online calculation.

\section{B. Lifetime Model}

Existing life models can be divided into two categories: analytic models and physical models. Physical models combine material strain analysis and aging data, it can deeply reflect the physical mechanism of lifetime, but the expression is complex and the parameters are difficult to obtain. Analytical models are established only by fitting the aging data. It does not reflect the physical relation of the aging process, but it is simple for application. The analytical model is the most widely used in life estimation, the studies of analytical models are shown as follows.

The main factors affecting the lifetime of power devices are the means junction temperature and junction temperature fluctuations according to the failure mechanism. In the manual of the SEMIKRON semiconductor, the relationship among the means junction temperature, junction temperature fluctuations and the number of IGBT thermal cycles is shown in Fig. 12 [57]. Analytical models based on the two factors, and the common analytic models are as follows: Coffin-Manson Model, Lesit Model, Norris-Landzberg Model and the most widely used Bayerer Model.

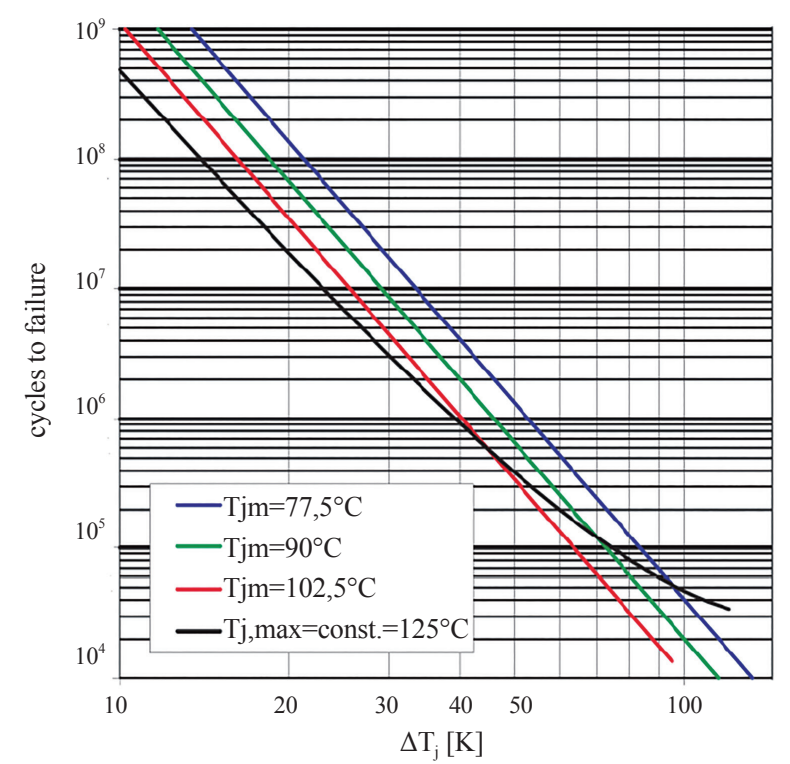

Fig. 12. Temperature cycle capability characteristic Nf for Standard SEMIKRON IGBT modules [57].

Coffin-Manson model only takes account of the fluctuation of the junction temperature $\Delta T_{\mathrm{j}}$, it can be expressed as follow [82]:

$$
N_{\mathrm{f}}=\alpha\left(\Delta T_{\mathrm{j}}\right)^{-n}
$$

Here $\alpha, n$ can be fitted by simulation or cyclic experiment. The model only suits to the condition what is the temperature fluctuations less than $120^{\circ} \mathrm{C}$, and there is only one factor is taken into consideration that results the low accuracy.

Another mathematical formulation of the Coffin-Manson model which besides the temperature variation $\Delta T_{\mathrm{j}}$ takes also into consideration the medium temperature $\mathrm{Tm}$ is shown in (3) [83].

$$
N_{\mathrm{f}}=a\left(\Delta T_{\mathrm{j}}\right)^{-n} e^{E \alpha /(k T m)}
$$

Here $k$ the Boltzmann constant and $E_{\mathrm{a}}$ the activation energy parameter.

On the basis of Coffin-Manson model, the influence of cycle frequency on the life is considered in Norris-Landzberg model [84], it can be written as:

$$
N_{\mathrm{f}}=A f^{-n_{2}}\left(\Delta T_{\mathrm{j}}\right)^{-n} e^{E_{\alpha} /\left(k T_{m}\right)}
$$

Here $f$ is the thermal cycle frequency; $n_{1}$ and $n_{2}$ are constant fitted by experimental data.

In addition to the medium temperature and temperature fluctuations, the the Bayerer model also takes into account the heating time ton, the load current $I$, the bonding wire diameter $D$ and the module block voltage $V$ [85], it can be written as follow:

$N_{\mathrm{f}}=K\left(\Delta T_{\mathrm{j}}\right)^{-\beta_{1}} e^{-\beta_{2} /\left(T_{\max }+274 K\right)} t_{t o n}^{\beta_{3}}+I^{-\beta_{4}}+V^{-\beta_{5}}+D^{-\beta_{6}}$

Here $T_{\text {jmax }}$ the maximum value of junction temperature, $K$ and $\beta$ are constant fitted by experimental data.

\section{Miner Linear Accumulation Damage Theory and Rain- flow Counting Algorithm}

The junction temperature of the power devices varies with the load variations, which leads to the cyclic thermal stress within the power devices, and fatigue failure of the power devices is the result what is a damage caused by accumulation of the thermal stress. Thereby, estimating the lifetime should consider the accumulation of damage. Miner linear accumulation damage theory is very simple, and has been widely used in lifetime estimation of power devices [86]. Lifetime estimation formula based on Miner linear cumulative damage theory can be written as:

$$
T=\frac{1}{D}
$$

Here $T$ is the number of cycles, $D$ is the cumulative damage for the $\mathrm{n}$ power cycles which is defined as follow:

$$
D=\sum_{i=1}^{n} \frac{n_{i}}{N_{i}}
$$


Here $D$ is the cumulative damage, $n_{\mathrm{i}}$ the number of cycles in the stress range $i$ and $N_{\mathrm{i}}$ the number of cycles to failure. When $D=1$, the device fails.

In order to count the number of cycles, the Rainflow Counting Algorithm is employed [87]. The Rainflow Counting Algorithm is a statistical method for analyzing the process of random load,the principle of counting is carried out on the basis of the stress-strain behavior of the material as shown in Fig. 13. It combines load reversals in a manner that defines a cycle as a closed hysteresis loop. Each closed hysteresis loop has a strain range and mean stress associated with it that can be compared with the constant amplitude [88].

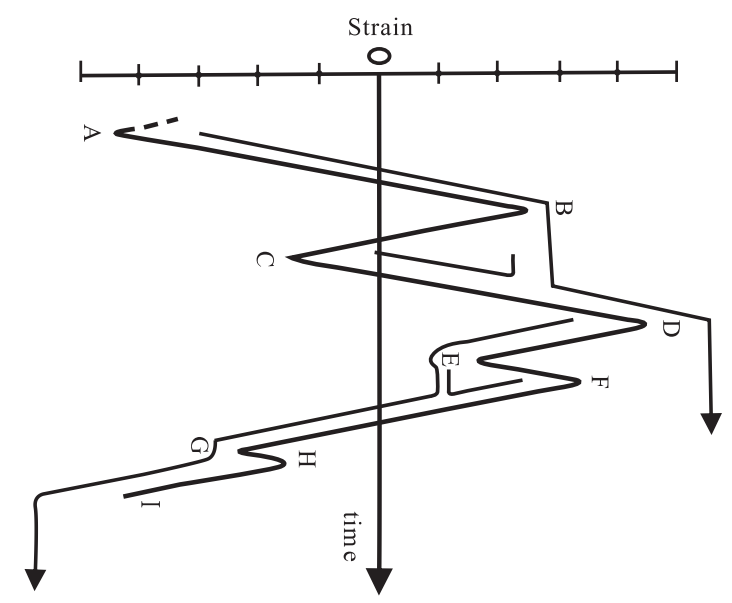

Fig. 13. Stress-strain cycles [88].

The flow of lifetime estimation is shown in Fig. 14. Firstly,extracting the junction temperature curve of the power device through converter mission profile.Secondly, gathering statistics of the types of thermal cycle and the number of each thermal cycle by Rainflow counting algorithm.Thirdly, calculating the total number of cycles that the power device can withstand for each thermal cycle through the life model. At last, the lifetime expectancy of the power device can be estimated based on Miner linear accumulation damage theory. In order to verify the effect of active thermal control, the lifetime expectancy can be calculated with and without active thermal control respectively by lifetime estimation technique, under the same operating condition.

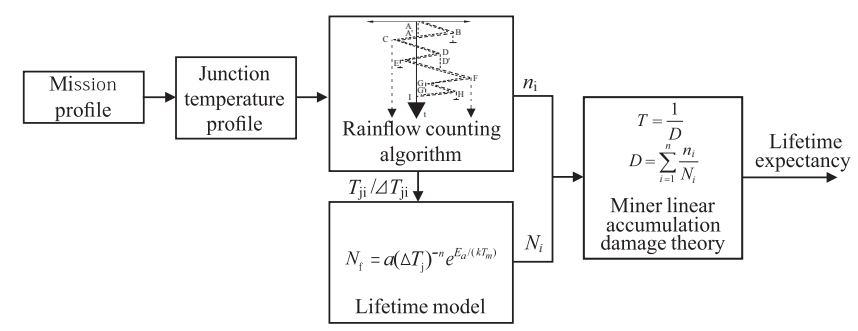

Fig. 14. The flow chart of lifetime estimation.

\section{Active Thermal Control}

In recent years, reports of active thermal control for power devices gradually increased, which is in order to reduce the thermal stress on the power devices,active thermal control is another way to improve the reliability of power devices. In those reports, methods of active thermal control can be divided into two categories by the basic ideas, which are refined by the principle of realization. The first kind of active thermal control method is based on the loss compensation, this kind of method is mainly for the junction temperature fluctuations caused by the converter input and output power changes, i.e. low frequency junction temperature fluctuations. Its basic idea is that when the power of converter is reduced, the loss of the power device can be compensated in real-time by controlling the loss-related variables, such as increase switch frequency, thus the magnitude of the junction temperature fluctuation is reduced.The mainly problem of the loss compensation is that it will increase the total loss of power devices and improves the average junction temperature of power devices.The second kind of active thermal control method is based on the loss reduction. Its basic idea is that according to the thermal load distribution of power devices divides the work interval of converter, when power devices work into the serious thermal load interval, the total loss can be reduced by decreasing the switching times,such as reducing the switching frequency etc. to reducing the thermal stress of power devices. This kind of method can reduce both the average junction temperature and junction temperature fluctuation at the same time.The mainly problem of the loss reduction is that the quality of the converter output will be reduced with decreasing the switching times, such as the converter output ripple current will increase with reducing the switching frequency. And if the converter is designed with minimum loss, this method cannot be applied. The latest researches progress of active thermal control are respectively outlined by the two basic concepts as follow.

\section{A. Loss Compensation}

Loss compensation is mainly for smoothing low frequency junction temperature fluctuations. The basic idea of loss compensation is that the loss-related variables such as switching frequency are usedto compensate for the internal loss fluctuations of power devices which is caused by the fluctuations of converter input and output power. As a result, loss compensation will increase the total loss of power devices, but the overall fluctuation of junction temperature can be significantly reduced with slightly increased mean temperature level. According to the lifetime models in Fig. 12, this is a more optimal loading condition with regard to lifetime extension. Loss compensation does not affect the fundamental frequency temperature fluctuation. There is no current flows through the power devices in the half-sinusoidal period, so that the base frequency junction temperature fluctuation is difficult to smooth by loss compensation. The methods of junction temperature on-line measurement are not yet ready wide application, the junction temperature estimation with the thermal network is used to loss compensation, and the quasi-close loop control such as look-up table is applied. 
A control scheme based on the junction temperature estimation is proposed as shown in Fig. 15 [89]. In the scheme the resulting junction temperature are calculated by the thermal network with the $P_{\text {loss }}$. Information such as load current $i_{c}$, the DC-link voltage $V_{\mathrm{dc}}$ and the case temperature $T_{\mathrm{c}}$ are measured in the physical system, they are taken to determine the collector to emitter voltage drop $V_{\text {ce }}$ and the switching energies $E_{\text {on }}$ and $E_{\text {off }}$ by the characteristic curves of power devices. They can be used to achieve an estimation of the conduction losses $P_{\text {cond }}$ and the switching losses $P_{\text {sw }}$. The thermal controller sets the switching frequency independent from the calculation result of $T_{\mathrm{j}}$. To filter the junction temperature's fluctuation of the fundamental frequency $f$ is used as an input.

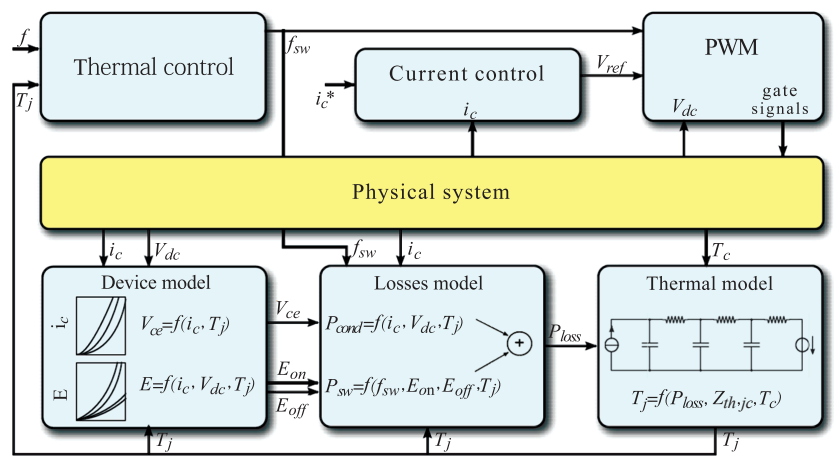

Fig. 15. Block scheme of the thermal control system [89].

\section{1) Switching Frequency Control}

The switching frequency is a loss dependent variable, which mainly affects the switching losses of power devices. The junction temperature of power devices reduces with the decreasing of load, then the switching losses are adjusted by increasing the switching frequency, so that the junction temperature fluctuation can be smoothed.This method does not need additional hardware [89]-[91].

A loss compensation method with controlling the switching frequency is proposed [90], and the control method of Fig. 14 is employed.The junction temperature with fixed switching frequency and with the active thermal control are shown in Fig. 16, they are acquired by a single-phase invert-

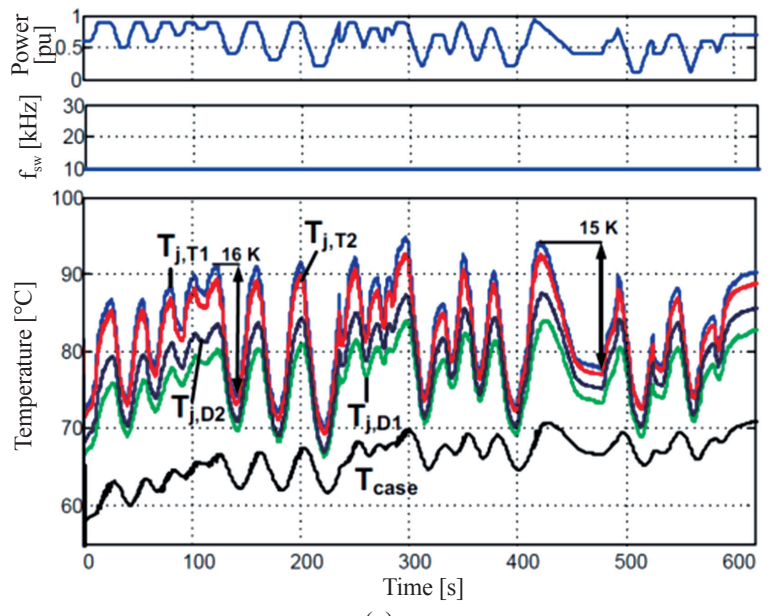

(a)

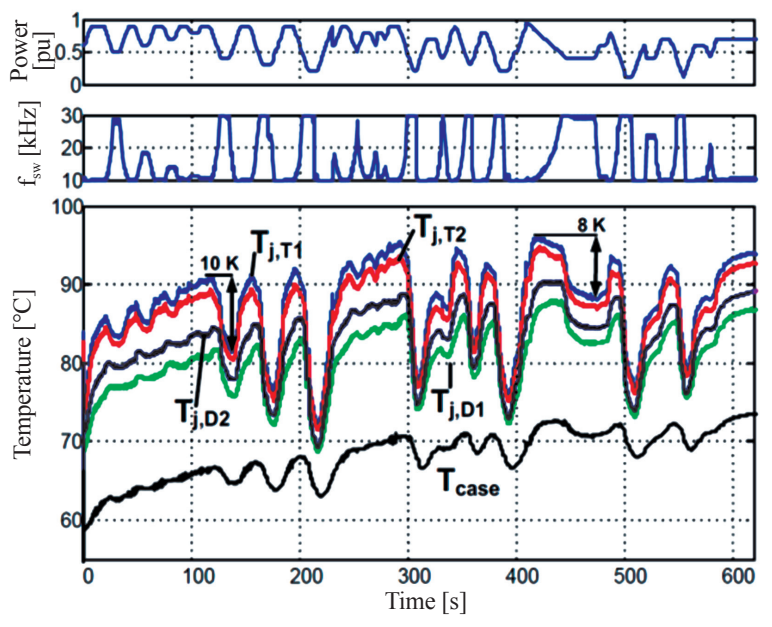

(b)

Fig. 16. Experimental result of the switching frequency control [90]:(a) Constant switching frequency. (b) Active thermal control using switching frequency variation between $10 \mathrm{kHz}$ and $30 \mathrm{kHz}$.

er. It can be seen that the maximum junction temperature fluctuation of the power device is reduced from $15 \mathrm{~K}$ to $8 \mathrm{~K}$.

\section{2) Gate Control}

Gate control is also a method of switching losses control. Gate voltage and the driving resistance have an effect on loss, the relationship among the gate voltage, resister and power devices lifetime has been estimated according to a real field mission profile [92]. Gate control does not affect the current ripple of the converter output, but gate control requires additional circuit.

Gate drive voltage affects switching loss and the saturation voltage, consequently the loss of power devices can be controlled. A temperature dependent driving strategy for power transistors is proposed which aimed at counterbalancing temperature related increases in their on-state resistance and power losses by a corresponding increase of the amplitude of the applied driving level [93]. But this method requires a precise control of the voltage level, which is too difficult to implement. This problem has been improved by [94]. The two-step gate drive unit is employed in [94], which divides the gate voltage into two levels. The switching loss and conduction loss of $\mathrm{GaN}$ can be adjusted by controlling the low level of time, at the same time the junction temperature is smoothed as shown in Fig. 17.

\section{3) Reactive Power Circulated}

In the parallel converter, the reactive power delivered can significantly influence the loading of components, and it is not restricted to the available mechanical/electrical power processed by the converter system, so that it is suitable to achieve active thermal control [95]. The reactive power will not only modify the phase angle between the output voltage and current of converter, but also modify the current amplitude flowing in the power devices, which are all related to the power loss and thermal loading of power devices. By introducing certain amount of underexcited reactive power 
to heat up the device during the low power period, the overall fluctuation of device temperature can be significantly reduced.Compared to switching frequency control or gate control, the disadvantage of reactive power cycling is that it can only be applied in the parallel converter system and the thermal load of the diode is increased.

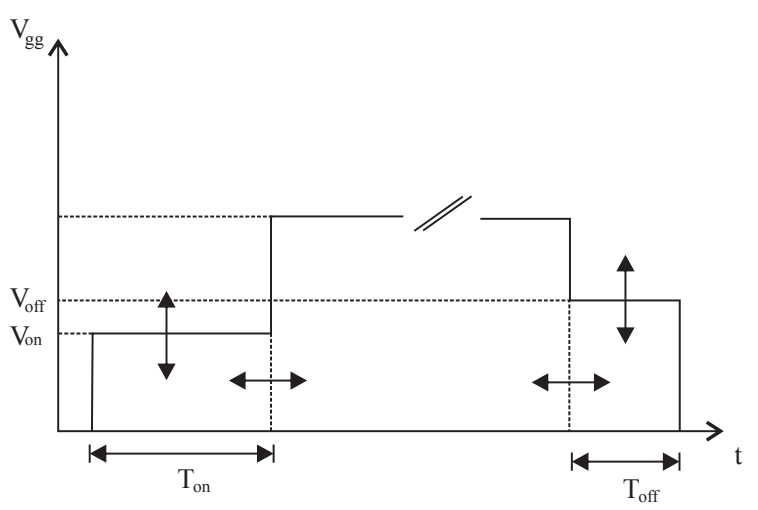

(a)

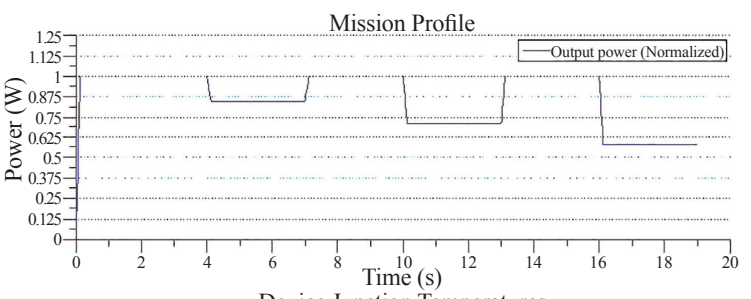
Device Junction Temperatures

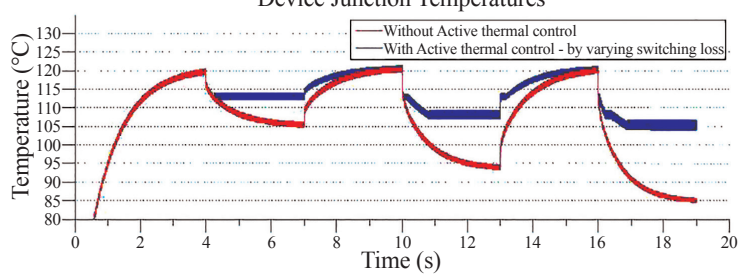

(b)

Fig. 17. Gate driver for the active thermal control of a DC/DC GaN-based converter [94]: (a) Waveform of the two-step gate driver; (b) Simulation results of active thermal control strategies.

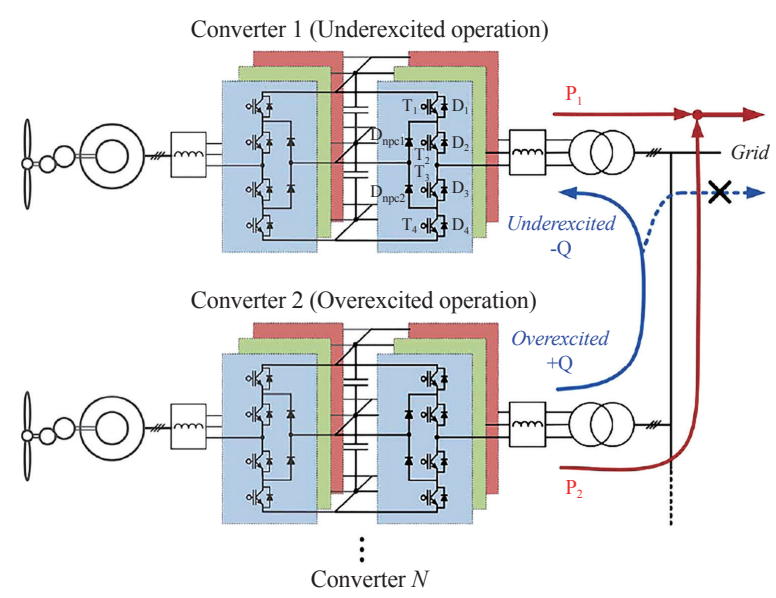

Fig. 18. Reactive power circulated in paralleled wind power converters [95].

\section{4) Power Sharing}

The existing solutions for paralleled converter operation focus on equal current sharing among the converters. Reference [96] provides a method of various publications for equal power distribution in the paralleled power electronics building blocks. The power distributions among paralleled power electronics building blocks can be adjusted by the junction temperature to improve the efficiency and the lifetime of semiconductor. The disadvantage of power sharing is as same of reactive power cycling, it also can only be applied in the parallel converter system.

\section{B. Loss Reduction}

The basic idea of loss reduction active thermal control is that the losses of power devices will be reduced by decreasing the switching times in the worst working environment. It can be achieved by adjusting some operating conditions, as dc-link voltage, modulation strategy and switching frequency, as a result the thermal stress on power electronic devices is reduced, the control flow chart of loss reduction is proposed as shown in Fig. 19 [97].

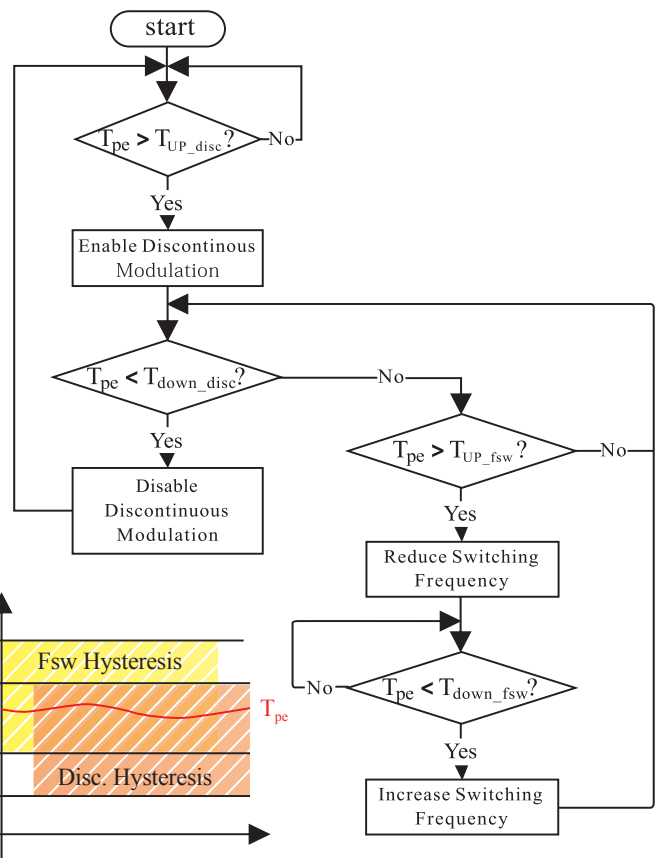

Fig. 19. State diagram for the hysteretic control[97].

\section{1) Switching Frequency and Current Limit}

Switching frequency hysteresis control is one method of loss reduction, the switching frequency is reduced to limit the junction temperature, in addition the load current is limited to prevent the junction temperature overheating [98][101]. In [102], a new approach for junction temperature estimation is investigated using an enhanced-Luenberger-style closed-loop observer. This technology can then be used as a sensor replacement technique for estimating junction tem- 
perature using a baseplate temperature sensor in the module, and also perform the active thermal control by switching frequency and current limit regulation as show in Fig. 20.
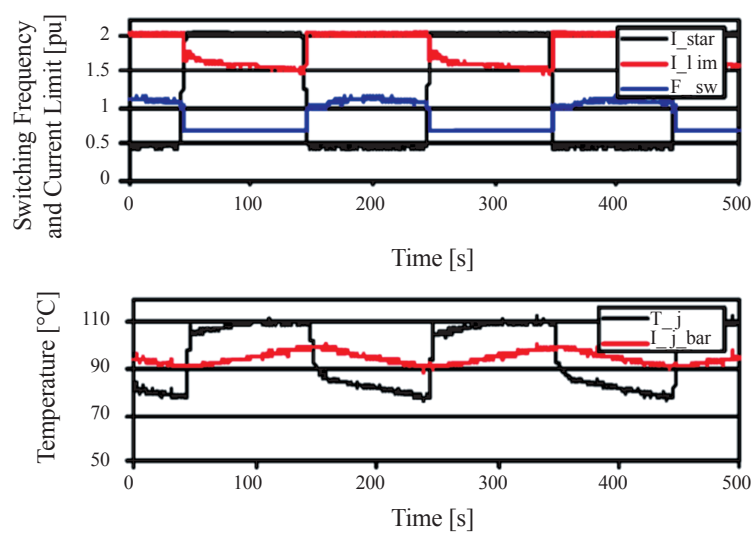

Fig. 20. Comparison of junction temperature with and without switching frequency control [102].

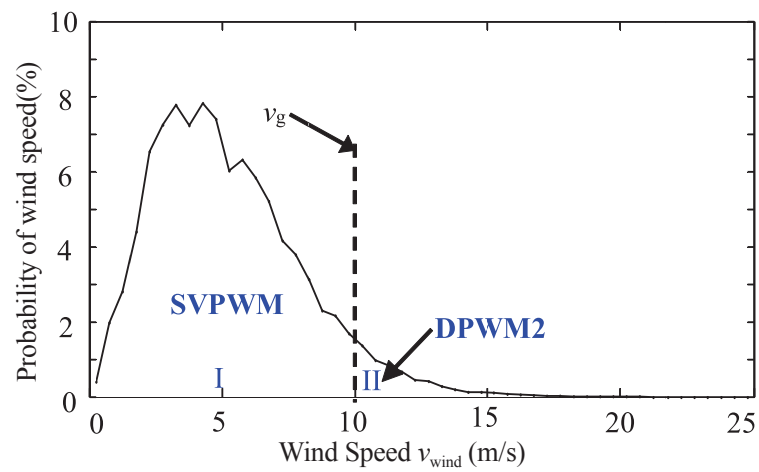

(a)

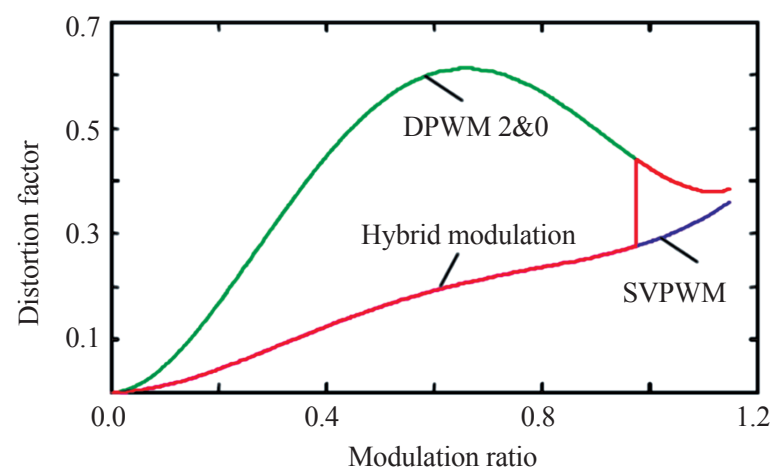

(b)

Fig. 21. The hybrid modulation method [105]:(a) the control strategy;(b) the influence of the power quality.

\section{2) Modulation Strategy}

Space vector modulation can be divided into continuous pulse width modulation (CPWM) and discontinuous pulse width modulation (DPWM). Compared with CPWM, the switching loss of the device is low if the DPWM is adopted, so that the junction temperature fluctuation is low. The $60^{\circ}$ discontinuous pulse width-modulation strategies allow better thermal performance and increase the estimated lifetime of the converter compared with SPWM modulation, when FT60 modulation is adopted, the average junction temperature of the device is lower, thereby improving the converter energy conversion efficiency [103], [104]. Although DPWM can improve the lifetime of power devices, it will reduce the
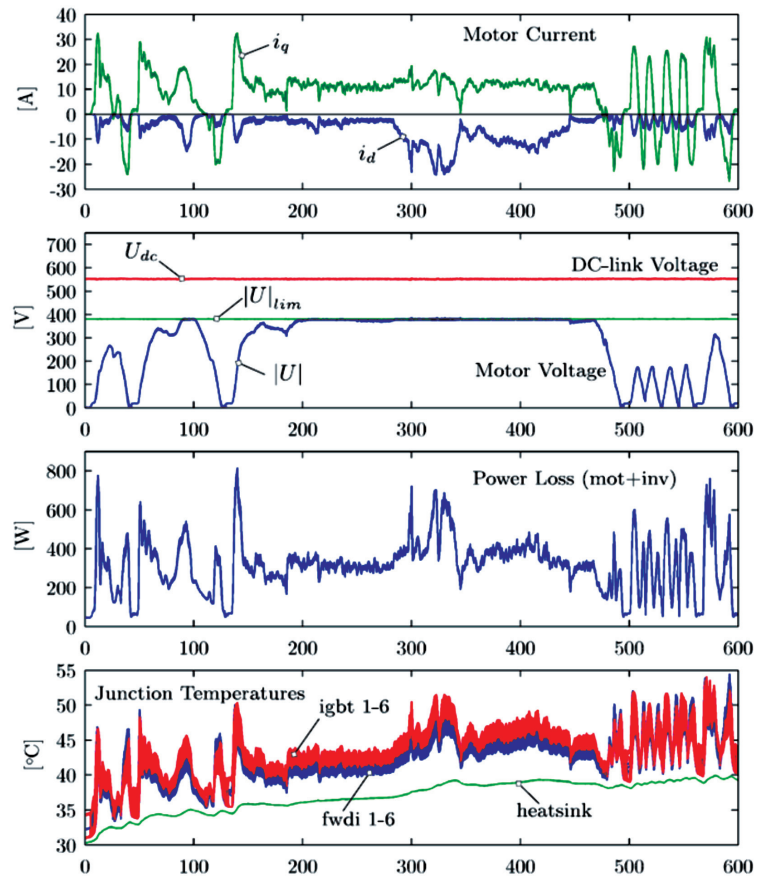

(a)
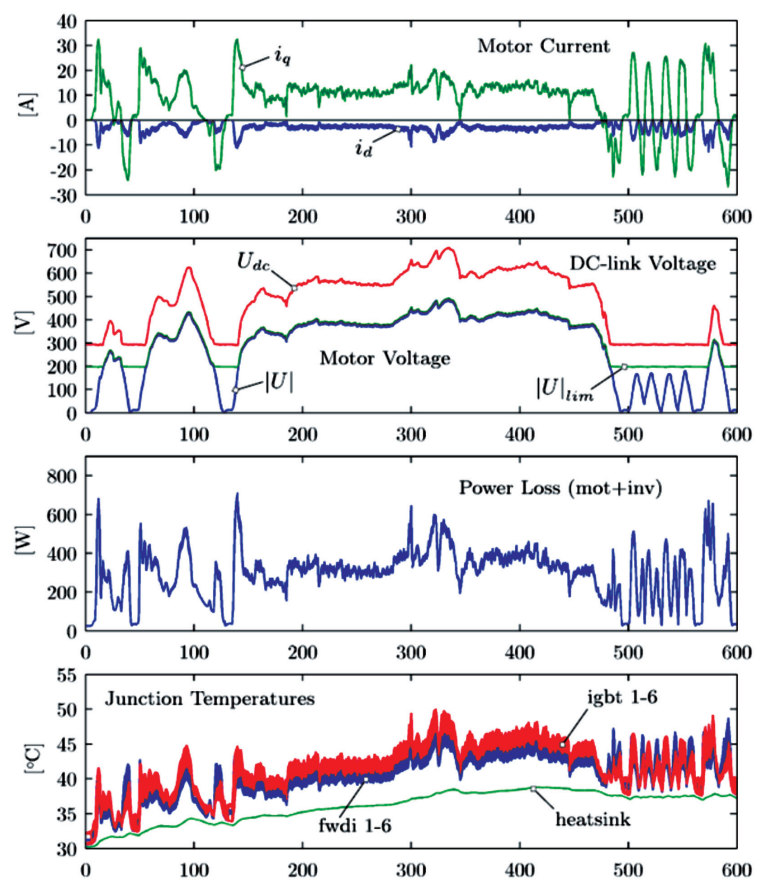

(b)

Fig. 22. Dynamic DC-link voltage adaptation for thermal management of traction drives [106]: (a) Fixed DC-link voltage: $U d c=550 \mathrm{~V}$; (b) Variable DC-link voltage: $\mathrm{Udc}=[290 \ldots 750] \mathrm{V}$. 
power quality of converter.In order to maximization reduction the impact of DPWM on the power quality, in the wind turbine system, a hybrid modulation method based on the wind speed distribution probability is proposed. This method makes the converter working mainly with the CPWM modulation, and the DPWM will be employed if the operating condition is worst, the control strategy and the influence are shown in Fig. 21 [105].

\section{3) DC-link Voltage Regulation}

In the traction drives with PMSM, the DC bus voltage is adjusted dynamically to reduce the loss [106]. The bus voltage level is adjusted to the required PMSM terminal voltage in each operating point. Consequently, switching losses can be reduced at low speed by lowering the bus voltage. At high speed, the voltage level is boosted and field-weakening operation and the associated additional losses are avoided. The junction temperature with the fixed DC-link voltage and with the variable DC-link voltageare shown in Fig. 22. It can be seen that the average junction temperature and junction temperature fluctuations are significantly reduced.

\section{Others}

In addition to the above categories, there are other methods of active thermal control have been reported, and all of their purpose is to reduce the junction temperature fluctuations.In the three-level neutral-point-clamped converter, the inner hexagon of the space vector diagram have switching redundancies which can be adopted to active thermal control. These switching redundancies provide the control flexibility to modify the current paths flowing in the power devices, and thereby modifying the conduction losses of the device. This feature is especially interesting for the ride-through operation during the grid faults for grid-tied converters, or the start-up operation of motor drives, where the voltage reference vector is normally low in amplitude and it is located in the inner hexagon [107], [108].The algorithm of a DC/DC converter for photovoltaic system was actively modified in order to limit the maximum junction temperature derivative in the presence of irradiation changes where the algorithm modifies the Maximum Power Point Tracking embedded in this kind of converters [109]. In fast varying irradiance environments, it is demonstrated in Fig. 23 to reduce the thermal cycling by not tracking very fast irradiance variations, which only slightly increase the harvested energy, but cause damage to the components. If there are no fast variations, the maximum power point is normally tracked by harvesting the maximum energy, as it is commonly done. To mitigate the effects of the ambient temperature variations, a regulation strategy of cooling is reportedin [110], which the speed of the fan is controlled.

The above approaches for active thermal control are summarized in Fig. 24 and their references are attached.This figure classifies the existing active thermal control methods from the perspective of the basic ideas and the means of implementation.Loss compensation methods can significantly

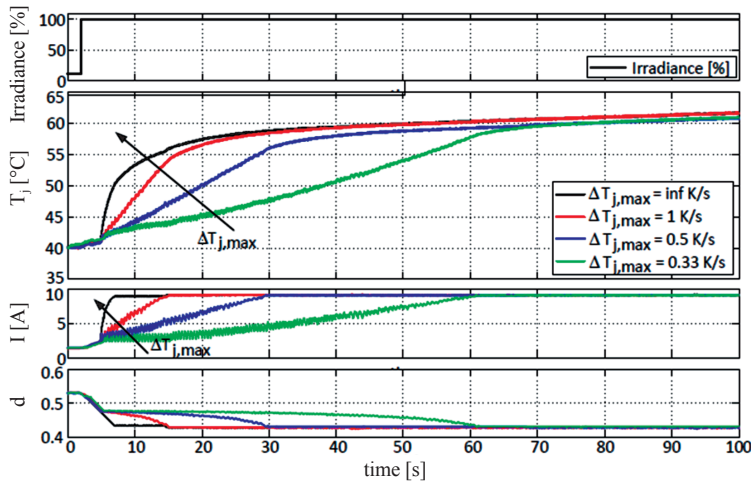

Fig. 23. Behavior of the MPPT for a step in the irradiance PPV,rel $=10 \% \geq P$ $\mathrm{PV}, \mathrm{rel}=100 \%$ for different temperature gradients and normalized starting temperature in one IGBT. Irradiance, junction temperature, input current and duty cycle of the boost converter are shown [109]

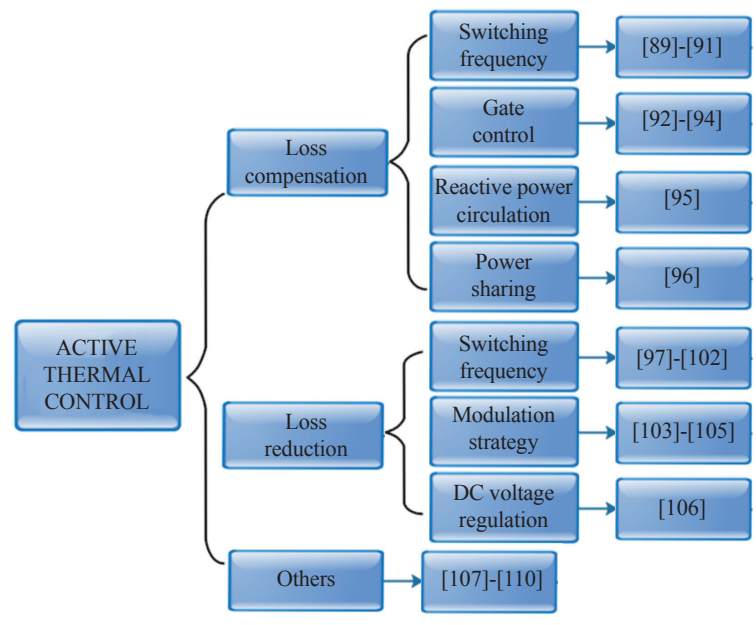

Fig. 24. Classification of active thermal control methods.

reduce the thermal stress caused by low frequency junction temperature fluctuations, but the main drawbacks include: 1) have no effect on the base frequency junction temperature fluctuations; 2) it will increase the average loss of power devices.Loss reduction methods can reduce thermal stress caused by both the fundamental frequency junction temperature fluctuations and low frequency junction temperature fluctuations,but the main drawbacks include: 1) it will reduce the output quality of the converter; 2 ) if the converter is designed with minimum loss, it will not be applied. Other active thermal control methods are mainly for specific applications and can effectively reduce the thermal stress under the specific condition, but they can not be promoted.

\section{Conclusion and Challenge}

Current studies of conditions monitoring generally revolve around IGBT modules, the conditions monitoring of the IGBT module can provide reference and basis for the optimization maintenance of power converter systems. On the basis of existing research, it is still necessary to find out more indicators that can reflect the health condition more comprehensively and understand the precursors' variation 
law more deeply. Meanwhile, the comprehensive health condition assessment based on multiple precursors is still of great importance. Furthermore, how to achieve the condition monitoring of power converters from the device level to the system-level is significant important.

Lifetime of power devices is estimated on the basis of the accelerated aging test, the junction temperature evaluation and the method of accumulation damage calculation. The existing IGBT lifetime models have their limitations due to the diversity of materials, the complexity of operating condition and the imperfection of accumulation damage theories. Consequently, it is too difficult to establish an accurate, universal IGBT life model, so that the material of the module and the operating conditions should be taken into account when building or using a lifetime model.Damage accumulation theory also needs to be developed so that lifetime models can get more accurate predictions, customers and manufacturers can be acquired more valid reference to do so.

In active thermal control, junction temperatures general are estimated by the case temperature and the thermal network, so that its control is quasi-closed loop and the actual junction temperature is ambiguous before or after active thermal control. The potential costs for higher losses or expense of control device etc.are must to be considered, if the potential costs are too high,active thermal control is of little significance. There is a trade-off between active thermal control and the potential costs. In addition, the effectiveness of active thermal control is verified by lifetime estimation at present, the real result of active thermal control is missing, and it is should to be verified with practical applications or accelerated tests.

\section{REFERENCES}

[1] B. Ji, X. Song, W. Meng, V. Pickert, and W. Cao,"Integrated condition monitoring for vehicle-ready power modules," in Transportation Electrification Asia-Pacific (ITEC Asia-Pacific), 2014 IEEE Conference and Expo, Beijing, 2014, pp. 1-6.

[2] I. Aharon and A. Kuperman,"Topological overview of powertrains for battery-powered vehicles with range extenders," IEEE Tans. Power Electron, vol. 26, no. 3, pp. 868-876, 2011.

[3] F. Blaabjerg, M. Liserre, and M. Ke,"Power electronics converters for wind turbine systems," Industry Applications, IEEE Transaction, vol. 48, no. 2, pp. 708-719, 2012.

[4] U. Scheuermann,"Reliability challenges of automotive power electronics," Microelectron.Reliab, vol. 49, no. 9-11, pp. 1319-1325, 2009.

[5] H. Lu, C. Bailey, and C. Yin,"Design for reliability of power electronics modules," Microelectron.Reliab, vol. 49, no. 9-11, pp. 1250$1255,2009$.

[6] B. Ji, V.Pickert, W. Cao, and B. Zahawi,"In situ diagnostics and prognostics of wire bonding," Power Electronics, IEEE Transaction, vol. 28 , no. 12 , pp. $5568-5577,2013$.

[7] M. Trivedi and K. Shenai, “Failure mechanisms of IGBT's under short-circuit and clamped inductive switching stress," IEEE Trans, Power Electron, vol. 14, no. 1, pp. 108-116, 1999.

[8] M. Musallam and C. M. Johnson,"Real-time compact thermal models for health management of power electronics," IEEE Trans, Power Electron, vol. 25, no. 6, pp. 1416-1425, 2010.

[9] D. Xiang, L. Ran, P. Tavner, S. Yang, A. Bryant, and P. Mawby, "Condition monitoring power module solder fatigue using inverter harmonic identification," IEEE Trans. Power Electron, vol. 27, no. 1, pp. 235-247, 2012.

[10] C. Mauro,"Selected failure mechanisms of modern power modules," Microelectron. Reliability, vol. 40, no. 4-5, pp. 653-667, 2002.

[11] B. Lu and S. K. Sharma,"A literature review of IGBT fault diagnostic and protection methods for power inverters," IEEE Trans. Industry Application, vol. 45, no. 5, pp. 1770-1777, 2009.

[12] S. Bernet, "Recent developments of high power converters for industry and traction applications," IEEE Trans, Power Electron, vol. 15, no. 6, pp. 1102-1117, 2000.

[13] L. Xiao and R. Li,"Research on the open-circuit fault diagnosis of transistor in inverter paralleling system," Proceedings of the CSEE, vol. 26, no. 4, pp. 99-104, 2006.

[14] M. Aalehifar, R. S. Arashloo, M. Moreno-Eguilaz, and V. Sala,"Open circuit fault detection based on emerging FCS-MPC in power electronics systems," in Power Electronics and Application(EPE) 2013 15th European Conference, Lille, 2013, pp. 1-10.

[15] J. Han, H. Liu, W. Yue, and N. Shen,"Fault detection method in micro-grid multi-pulse thyristor rectifier circuit," in Power and Energy Engineering Conference(APPEEC),2012 Asia-Pacific., Shanghai, 2012, pp. 1-4.

[16] R. T. Davis and D. J. Sprenger,"Methodology and apparatus for rapid power cycle accumulation and in-situ incipient failure monitoring for power electronics modules," in Electronic Components and Technology Conference(ECTC), 2014 IEEE 64th., Orlando, 2014, pp. 1996-2002.

[17] G. Coquery and R. Lallemand,"Failure criteria for long term accelerated power cycling test linked to electrical turn off SOA on IGBT module," Microelectronics Reliability, vol. 40, no. 8-10, pp. 1665 1670,2000

[18] Y. Avenas, L. Dupont, N. Baker et al., "Condition monitoring: A decade of proposed techniques," IEEE Industrial Electronics Magazine, vol. 9, no. 4, pp. 22-36, 2015.

[19] Z. Wang and J. Liu. Power Electronics, fifthed., Beijing: China Machine Press, 2009, p. 7.

[20] S. Yang, D. Xiang, A. Bryant, P. Mawby, L. Ran, and P. Tavner, "Condition monitoring for device reliability in power electronic converter," IEEE Trans. Power Electronics, vol. 25, no. 11, pp. 2734-2752, 2010.

[21] W. A. Koziarz and D. A. Gilmour,"Anomalous thermal conductivity in regions of nonuniform die attach integrity," in Reliability Physics Symposium 1995, 33th Annual Proceedings, IEEE International., Las Veas, 1995, pp. 107-111.

[22] H. Oh, B. Han, P. McCleskey, C. Han, and B. D. Youn,"Physics-of-failure, condition monitoring and prognostics of insulated gate bipolar transistor modules: A review," IEEE Transactions, Power Electronic, vol. 30, no. 5, pp. 2413-2426, 2014.

[23] W. Lai, M. Chen, L. Ran et al.,"Experimental investigation on the effects of narrow junction temperature cycles on die-attach solder layer in an IGBT module," IEEE Transactions on Power Electronics, vol. 32, no. 2, pp. 1431-1441, 2016.

[24] J. R. Celaya, P. Wysocki, V. Vashchenko et al.,"Accelerated aging system for prognostics of power semiconductor devices," in Autotestcon. IEEE, 2010, pp.1-6.

[25] P. Sun, C. Gong, X. Du et al.,"Condition monitoring IGBT module bond wires fatigue using short-circuit current identification," IEEE Transactions on Power Electronics, vol. 32, no. 5, pp. 3777-3786, May 2016.

[26] M. Du, K.Wei, J. Li et al.,"Condition monitoring IGBT module bond wire lift-off using measurable signals," in Power Electronics and Motion Control Conference. IEEE, 2012, pp. 1492-1496.

[27] S. Zhou, L. Zhou, and P. Sun,"Monitoring potential defects in an IGBT module based on dynamic changes of the gate current," IEEE Transactions on Power Electronics, vol. 28, no. 3, pp. 1479-1487, 2013.

[28] R. Schmidt and U. Scheuermann,"Using the chip as a temperature sesor-The influence of steep lateral temperature gradients on the Vce(T) - measurement," in Power Electronics and Applications, 2009, 13th European Conference., Barcelona, 2009, pp. 1-9.

[29] N. Patil, J. Celaya, D. Das, K. Goebel, and M. Peche,"Precursor parameter identification for insulated gate bipolar transistor(IGBT) prognostics," Reliability, IEEE Transactions, vol. 58, no. 2, pp. 271- 
276, 2009.

[30] P. Ghimire, A. Ruiz de Vega, S. Munk-Nielsen, B. Rannestad, and P. B. Thogersen, "A real time Vce measurement for high power IGBT module in converter operation," in Future Energy Electronics Conference (IFEEC), Tainan, 2013, pp. 761-766.

[31] Y. Xiong, X. Cheng, Z. J. Shen et al.,"Prognostic and warning system for power-electronic modules in electric, hybrid electric, and fuel-cell vehicles," IEEE Transactions on Industrial Electronics, vol. 55 , no. 6, pp. 2268-2276, 2008

[32] V. Smet, F. Forest, J. J. Huselstein et al.,"Ageing and failure modes of IGBT modules in high-temperature power cycling," IEEE Transactions on Industrial Electronics, vol. 58, no. 10, pp. 4931-4941, 2011.

[33] U. M. Choi, S. Joergensen, and F. Blaabjerg, "Advanced accelerated power cycling test for reliability investigation of power device modules," IEEE Transactions on Power Electronics, vol. 31, no. 12, p.1, 2016.

[34] U. M. Choi, F. Blaabjerg, S. Munk-Nielsen et al.,"Reliability improvement of power converters by means of condition monitoring of IGBT modules," IEEE Transactions on Power Electronics, vol. 32, no. 10 , pp.7990-7997, Oct. 2016

[35] A. Singh, A. Anurag, and S. Anand,"Evaluation of Vce at inflection point for monitoring bond wire degradation in discrete packaged IGBTs," IEEE Transactions on Power Electronics, vol. 32, no. 4, pp. 2481-2484, Apr. 2016.

[36] P. Sun, C. Gong, X. Du et al.,"Online condition monitoring for both IGBT module and DC-link capacitor of power converter based on short-circuit current simultaneously," IEEE Transactions on Industrial Electronics, vol. 64, no. 5, pp. 3662-3671, 2017.

[37] N. Patil, D. Das, G. Kai et al.,"Identification of failure precursor parameters for insulated gate bipolar transistors (IGBTs)," in International Conference on Prognostics and Health Management.IEEE, 2008, pp. 1-5.

[38] S. Dusmez, S. H. Ali, M. Heydarzadeh et al.,"Aging precursor identification and lifetime estimation for thermally aged discrete package silicon power switches," IEEE Transactions on Industry Applications, vol. 53, no. 1, pp. 251-260, 2017.

[39] M. A. Eleffendi and C. M. Johnson,"Evaluation of on-state voltage $\mathrm{V} \mathrm{CE}(\mathrm{ON})$, and threshold voltage $\mathrm{V}$ th, for real-time health monitoring of IGBT power modules," in European Conference on Power Electronics and Applications. IEEE, 2015, pp. 1-10.

[40] L. Ren, C. Gong, Q. Shen et al.,"A method for health monitoring of power MOSFETs based on threshold voltage," in Industrial Electronics and Applications. IEEE, 2015, pp. 1729-1734.

[41] K. Wei, M. Du, L. Xie et al.,"Study of bonding wire failure effects on external measurable signals of IGBT module," IEEE Transactions on Device \& Materials Reliability, vol. 14, no. 1, pp. 83-89, 2014.

[42] J. R. Celaya, A. Saxena, S. Saha, V. Vashchenko, and K. Goebel,"Prognostics of power MOSFET," in 2011 IEEE 23rd International Symposium on Power Semiconductor Devices and ICs, San Diego, CA, 2011, pp. 160-163.

[43] D. W. Brown, M. Abbas, A. Ginart et al.,"Turn-off time as an early indicator of insulated gate bipolar transistor latch-up," IEEE Transactions on Power Electronics, vol. 27, no. 2, pp. 479-489, 2012.

[44] A. Hensler, C. Herold, J. Lulz, and M. Thoben,"Thermal impedance monitoring during power cycling tests," in PCIM Europe 2011, Nuremberg, 2011, pp. 241-246.

[45] B. Tian, W. Qiao, Z. Wang, T. Gachovska, and J. L. Hudgins, "Monitoring IGBT's health condition via junction temperature variations," in Applied Power Electronics Conference and Exposition (APEC)., Fort Worth, 2014, pp. 2550-2555.

[46] P. Ghimire, S. Beczkowski, S. Munk-Nielsen, B. Rannestad, P. B. Thogersen, "A review on real time physical measurement techniques and their attempt to predict wear-out status of IGBT," in Power Electronics and Applications (EPE), 2013 15th European Conference, Lille, 2013, pp. 1-10.

[47] L. Li, Y. Xu, Z. Li et al.,"The effect of electro-thermal parameters on IGBT junction temperature with the aging of module," Microelectronics Reliability, vol. 66, pp. 58-63, Nov. 2016.

[48] B. Ji, X. Song, W. Cao et al.,"In situ diagnostics and prognostics of solder fatigue in IGBT modules for electric vehicle drives," IEEE Transactions on Power Electronics, vol. 30, no. 3, pp. 1535-1543, 2014.

[49] X. Du, T. Li, J. Zhang et al.,"Thermal network parameter identification of IGBT module based on the cooling curve of junction temperature," in Applied Power Electronics Conference and Exposition. IEEE, 2016, pp. 2992-2997.

[50] M. A. Rodriguez-Blanco, A. Claudio-Sanchez, D. Theilliol, L. G.Vela-Caldes, P. Sibaja-Teran, L. Hernandez-Gonzalez, and J. Aguayo-Alquicira, "A failure-detection strategy for IGBT based on gate-voltage behavior applied to a motor drive system," Industrial Electronics, IEEE Transactions, vol. 58, no. 5, pp. 1625-1633, 2011.

[51] V. Sundaramoorthy, E. Bianda, R. Bloch, I. Nistor, G. Knapp, and A. Heinemann, "Online estimation of IGBT junction temperature $(\mathrm{Tj})$ using gate-emitter voltage at turn-off," in Power Electronics and Applications (EPE), 2013 15th European Conference, Lille, 2013, pp. $1-10$.

[52] H. Luo, Y. Chen, P. Sun et al.,"Junction temperature extraction approach with turn-off delay time for high-voltage high-power IGBT modules," IEEE Transactions on Power Electronics, vol. 31, no. 7, pp. 5122-5132, 2016.

[53] Y. Chen, H. Luo, W. Li et al.,"Analytical and experimental investigation on a dynamic thermo-sensitive electrical parameter with maximum dIC/dt during turn-off for high power trench gate/fieldstop IGBT modules," IEEE Transactions on Power Electronics, vol. 32, no. 8, pp. 6394-6404, Aug. 2017.

[54] D. Xiang, R. Li, P. Tavener, A. Bryant, S. Yang, and P. Mawby,“Monitoring solder fatigue in a power module using case-above-ambient temperature rise," Industry Applications, IEEE Transactions, vol. 47, no. 6, pp. 2578-2591, 2011.

[55] Z. Wang, B. Tian, W. Qiao et al.,"Real-time aging monitoring for IGBT modules using case temperature," IEEE Transactions on Industrial Electronics, vol. 63, no. 2, pp.1168-1178, 2016.

[56] V. K. Sundaramoorthy, E. Bianda, M. Kamel, G. J. Riedel, and I. Nistor, "Online junction temperature estimation for IGBT modules with paralleled semiconductor chips," Power Electronics, Machines and Drives (PEMD), 2014 7th IET International Conference, Manchester, 2014.

[57] D. Xiong, L. Gaoxian, L. Tengfei et al., "Multi-time scale lifetime evaluation of IGBT modules in the wind power converter," in Proceedings of the CSEE, vol. 35, no. 23, pp. 6152-6161, 2015.

[58] Wintrich, U. Nicolai, W. Tursky, and T. Reimann, "Semikron, application manual power semiconductors," Ilmenau: ISLE, 2011.

[59] J. Berner, "Load-cycling capability of HiPak IGBT modules," in ABB Application Note 5SYA 2043-02, 2012.

[60] X. Perpina, X. Jorda, M. Vellvehi, J. Rebollo, and M. Mermet-Guyennet, "Long-term reliability of railway power inverters cooled by heat-pipe-based systems," IEEE Transactions on Industrial Electronics, vol. 58, no.7, pp. 2662-2672, 2011.

[61] J. P. Bazzoa, T. Lukasievicz, M. Vogt, V. Oliveira, H. J. Kalinowski, and J. C. Cardozo Silva,"Monitoring the junction temperature of an IGBT through direct measurement using a fiber Bragg grating," International Conference on Optical Fiber Sensors, Ottawa, Canada, 2011.

[62] U. Scheuermann and R. Schmidt,"Investigations on the VCE(T) -Method to determine the junction temperature by using the chip itself as sensor," Intelligent Motion and Power Quality (PCIM 2009) Europe, Nuremberg, Germany, May 2009, pp.1-3.

[63] L. Dupont, Y. Avenas, and P.-O. Jeannin, "Comparison of junction temperature evaluations in a power IGBT module using an IR camera and three thermo-sensitive electrical parameters," IEEE Twenty-Seventh Annual Applied Power Electronics Conference and Exposition (APEC), Orlando, Florida, USA, Feb. 2012, pp.182-189.

[64] Y. Avenas and L. Dupont, "Evaluation of IGBT thermo-sensitive electrical parameters under different dissipation conditions-comparison with infrared measurements," Microelectronics Reliability, vol. 52, no. 11, pp. 2617-2626, 2012.

[65] H. Kuhn and A. Mertens, "On-line junction temperature measurement of IGBTs based on temperature sensitive electrical parameters," 13th European Conference on Power Electronics and Applications (EPE 2009), Barcelona, Spanish, Sept. 2009. 
[66] Y. Avenas, L. Dupont, and Z. Khatir, "Temperature measurement of power semiconductor devices by thermo-sensitive electrical parameters-A review," IEEE Transactions on Power Electronics, vol. 27, no. 6, pp. 3081-3092, 2012.

[67] Z. Xu, F. Wang, and P. Ning, "Junction temperature measurement of IGBTs using short circuit current" IEEE Energy Conversion Congress and Exposition (ECCE 2012), Raleigh, USA, Sept.2012.

[68] M. M. R. Ahmed and G. A. Putrus,"A method for predicting IGBT junction temperature under transient condition," in Proceeding of the 34th IEEE Annual Conference of Industrial Electronics, Orlando, Florida, USA, 2008, pp. 454-459.

[69] H. Wang, A. M. Khambadkone, and X. Yu, "Control of parallel connected power converters for low voltage microgrid-Part II: Dynamic electrothermal modeling," IEEE Transactions on Power Electronics, vol. 25, no. 12, pp. 2971-2980, 2010.

[70] S. Azuma, M. Kimata, M. Seto, X. Jiang, H. Lu, D. Xu, and L. Huang, "Research on the power loss and junction temperature of power semiconductor devices for inverter," in Proceedings of the IEEE International Conference on Vehicle Electronics, Changchun, China, 1999, pp.183-187.

[71] D. Xu, H. Lu, L. Huang, S. Azuma, M. Kimata, and R. Uchida, "Power loss and junction temperature analysis of power semiconductor devices," IEEE Transactions on Power Electronics, vol. 38, no. 5, pp. 1426-1431, 2002.

[72] Dimensioning program IPOSIM for loss and thermal calculation of Infineon IGBT modules. Technical Documentation. [Online]. Available: http: //www. Infineon.com.

[73] F. Profumo, A. Tenconi, S. Facelli, and B. Passerini, "Instantaneous junction temperature evaluation of high-power diodes (thyristor) during current transients," IEEE Transactions on Power Electronics, vol. 14, no. 2, pp. 292-299, 1999.

[74] P. E. Bagnoli, C. Casarosa, M. Ciampi, and E. Dallago, “Thermal resistance analysis by induced transient (TRAIT) method for power electronic devices thermal characterization-Part I. Fundamentals and theory," IEEE Transactions on Power Electronics, vol. 13, no. 6, pp. 1208-1219, 1998 .

[75] T. H. Duong, A. R. Hefner, and K. D. Hobart,"Electro-thermal simulation and design of a $60 \mathrm{~A}, 4.5 \mathrm{kV}$ half-bridge Si IGBT/SiC JBS hybrid power module," IEEE Energy Conversion Congress and Exposition, Raleigh, NC, USA, 2012.

[76] F. Carastro, A. Castellazzi, J. Clare, and P. Wheeler,"High-efficiency high-reliability pulsed power converters for industrial processes," IEEE Transactions on Power Electronics, vol. 27, no. 1, pp. 37-45, 2012 ..

[77] J. Lv, Z. Cao, N. FrÖhleke, J. BÖcker, H. Yuan, and H. Mi, "Thermal-electrical averaging model of resonant converters based on extended describing function method," IET Power Electronics, vol. 6, no. 1, pp.175-182, 2013.

[78] H. Chen, B. Ji, V. Pickert, and W. Cao, "Real-time temperature estimation for power MOSFETs considering thermal aging effects," IEEE Transactions on Device and Materials Reliability, vol. 14, no. 1, pp. 220-228, 2014.

[79] I. Swan, A. Bryant, P. A. Mawby, T. Ueta, T. Nishijima, and K. Hamada,"A fast loss and temperature simulation method for power converters, part II: 3-D thermal model of power module," IEEE Transactions on Power Electronics, vol. 27, no.1, pp. 258-268, 2012.

[80] B. Du, J. L. Hudgins, E. Santi, A. T. Bryant, P. R. Palmer, and H. A. Mantooth, "Transient electrothermal simulation of power semiconductor devices," IEEE Transactions on Power Electronics, vol. 25, no.1, pp. 237-248, 2010.

[81] J. Reichl, J. M. Ortiz-Rodríguez, A. Hefner, and J.-S. Lai, “3D thermal component model for electro-thermal analysis of multichip power modules with experimental validation," IEEE Transactions on Power Electronics, vol. 30, no. 6, pp. 3300-3308, 2015.

[82] S. S. Manson, "Thermal stress and low cycle fatigue," New York: McGraw-Hill, 1966.

[83] I. F. Kovacevic, U. Drofenik, and W. Kolar, "New physical model for lifetime estimation of power modules," International Power Electronics Conference, 2010.

[84] K. C. Norris and A. H. Landzberg,"Reliability of controlled collapse interconnections," IBM Journal of Research and Development, vol.
13, no. 3, pp. 266-271, 1969.

[85] R. Bayerer, T. Hermann, et al., "Model for power cycling lifetime of IGBT modules-various factors influencing lifetime," in Proceedings of the 5th International Conference on Integrated Power Electronics Systems(CIPS), Nuremberg, Germany,2008.

[86] M. A. Miner, "Cumulative damage in fatigue," J. Appl. Mech. Trans. ASME, vol. 12, pp. A159-A164, 1945.

[87] I. Rychlik, "A new definition of the rainflow cycle counting method," International Journal of Fatigue, vol. 9, no. 2, pp. 119-121, 1987.

[88] M. Musallam and C. M. Johnson, "An efficient implementation of the rainflow counting algorithm for life consumption estimation," IEEE Trans. Reliability, vol. 61, no .4, pp. 978-986, Dec. 2012.

[89] J. Falck, M. Andresen, and M. Liserre, "Active thermal control of IGBT power electronic converters," in Proc. of 201541 st Annual Conference of the IEEE Industrial Electronics Society, IECON 2015. IEEE, 2015, pp. 000001-000006.

[90] M. Andresen, G. Buticchi, J. Falck, M. Liserre, and O. Muehlfeld, "Active thermal management for a single-phase h-bridge inverter employing switching frequency control," in Proc. of PCIM Europe 2015; International Exhibition and Conference for Power Electronics, Intelligent Motion, Renewable Energy and Energy Management, May 2015, pp.1-8.

[91] J. Wu, L. Zhou, P. Sun et al., "Smooth control of insulated gate bipolar transistors junction temperature in a small-scale wind power converter," IET Power Electronics, vol. 9, no. 3, pp. 393-400, 2016.

[92] C. Sintamarean, H. Wang, F. Blaabjerg, and F. Iannuzzo, "The impact of gate-driver parameters variation and device degradation in the pvinverter lifetime," in Proc. of 2014 IEEE Energy Conversion Congress and Exposition (ECCE), Sept. 2014, pp. 2257-2264.

[93] L. Wu and A. Castellazzi, "Temperature adaptive driving of power semiconductor devices," in Proc. of 2010 IEEE International Symposium on Industrial Electronics, Jul. 2010, pp. 1110-1114.

[94] P. K. Prasobhu, G. Buticchi, S. Brueske, and M. Liserre, "Gate driver for the active thermal control of a dc/dc gan-based converter," in Proc. of 2016 IEEE Energy Conversion Congress and Exposition (ECCE), 2016.

[95] K. Ma, M. Liserre, and F. Blaabjerg, "Reactive power influence on the thermal cycling of multi-mw wind power inverter," IEEE Transactions on Industry Applications, vol. 49, no. 2, pp. 922-930, Mar. 2013.

[96] W. Huanhuan, A. M. Khambadkone, and Y. Xiaoxiao,"Control of parallel connected power converters for low voltage microgridPart II: Dynamic electrothermal Modeling," IEEE Transactions on Power Electronics, vol. 25, pp. 2971-2980, Dec. 2010.

[97] G. L. Calzo, A. Lidozzi, L. Solero, F. Crescimbini, and V. Cardi, "Thermal regulation as control reference in electric drives," in Proc. of 2012 15th International Power Electronics and Motion Control Conference (EPE/PEMC). IEEE, 2012, pp. DS2c-18.

[98] J. Lemmens, P. Vanassche, and J. Driesen, "Optimal control of traction motor drives under electrothermal constraints," IEEE Journal of Emerging and Selected Topics in Power Electronics, vol. 2, no. 2, pp. 249-263, Jun. 2014.

[99] J. Lemmens, J. Driesen, and P. Vanassche, "Thermal management in traction applications as a constraint optimal control problem," in Proc. of 2012 IEEE Vehicle Power and Propulsion Conference, Oct 2012, pp. 36-41.

[100] L.Wei, J. McGuire, and R. A. Lukaszewski, “Analysis of PWM frequency control to improve the lifetime of pwm inverter," IEEE Transactions on Industry Applications, vol. 47, no. 2, pp. 922-929, Mar. 2011.

[101] M. Weckert and J. Roth-Stielow, "Lifetime as a control variable in power electronic systems," in Proc. of 2010 Emobility-Electrical Power Train, Nov. 2010, pp. 1-6.

[102] D. Murdock, J. Torres, J. Connors, and R. Lorenz, “Active thermal control of power electronic modules," IEEE Transactions on Industry Applications, vol. 42, no. 2, pp. 552-558, Mar. 2006.

[103] S. Bifaretti, L. Tarisciotti, A. Watson, P. Zanchetta, A. Bellini, and J. Clare, "Distributed commutations pulse-width modulation technique for highpower AC/DC multi-level converters," IET Power Electron., vol. 5, no. 6, pp. 909-919, Jul. 2012. 
[104] M. Weckert, J. Roth-Stielow, “Chances and limits of a thermal control for a three-phase voltage source inverter in traction applications using permanent magnet synchronous or induction machines," in Proceedings of the 14th European Conference on Power Electronics and Applications (EPE 2011), Birmingham, UK, 2011.

[105] X. Du, G. Li, T. Li et al., "A hybrid modulation method for improving the lifetime of power modules in the wind power converter," Proceedings of the CSEE, vol. 35, no. 19, pp. 5003-5012, 2015.

[106] J. Lemmens, J. Driesen, and P. Vanassche, "Dynamic dc-link voltage adaptation for thermal management of traction drives," in Energy Conversion Congress and Exposition (ECCE), 2013 IEEE, Sept. 2013, pp. 180-187.

[107] K. Ma and F. Blaabjerg, "Thermal optimised modulation methods of three-level neutral-point-clamped inverter for $10 \mathrm{mw}$ wind turbines under low-voltage ride through," IET Power Electronics, vol. 5, no. 6, pp. 920-927, Jul. 2012.

[108] K. Ma and F. Blaabjerg, "Modulation methods for neutral-pointclamped wind power converter achieving loss and thermal redistribution under low-voltage ride-through," IEEE Transactions on Industrial Electronics, vol. 61, no. 2, pp. 835-845, Feb. 2014.

[109] M. Andresen, G. Buticchi, and M. Liserre, "Thermal stress analysis and mppt optimization of photovoltaic systems," IEEE Transactions on Industrial Electronics, vol. 63, no. 8, pp. 4889-4898, Aug. 2016.

[110] X. Wang, A. Castellazzi, and P. Zanchetta, "Regulated cooling for reduced thermal cycling of power devices," in Power Electronics and Motion Control Conference (IPEMC), 2012 7th International, vol. 1, Jun. 2012, pp. 238-244.

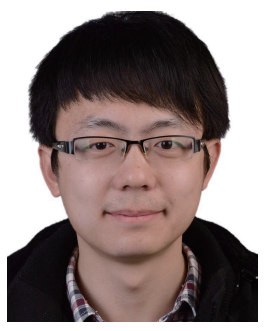

Bo Wang received the B.E degree in automation from the Beijing University of Technology, Beijing, China, and the M.S. degree in measurement technology and instruments from the Chongqing University of Technology, Chongqing, China, in 2010 and 2013, respectively. He is currently working toward the Ph.D. degree in electrical engineering at Chongqing University, Chongqing. His research interests include reliability and junction temperature management of insulated-gate bipolar

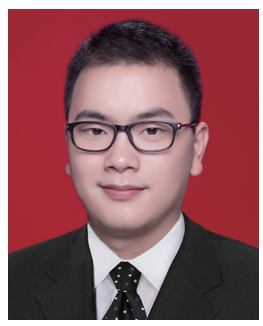

Jie Cai received the B.S. degree in electrical engineering from Chongqing University, Chongqing, China, in 2015. He is currently working toward the Ph.D. degree in electrical engineering at Chongqing University, Chongqing, China. His research interests include reliability and online monitoring of power electronic module.

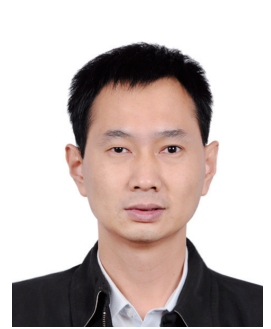

Xiong Du received the B.S., M.S., and Ph.D degrees from Chongqing University, Chongqing, China, in 2000, 2002, and 2005, respectively, all in electrical engineering. Since 2002, he has been with Chongqing University, where he is currently a Full Professor in the College of Electrical Engineering. From July 2007 to July 2008, he was a Visiting Scholar at Rensselaer Polytechnic Institute. His research interests include switching power converters, power quality control, and renewable energy power conversion. Dr. Du received the National Excellent Doctoral Dissertation of China in 2008.

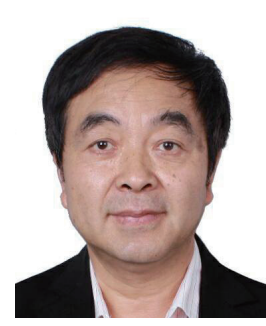

Luowei Zhou received the B.S., M.S., and Ph.D. degrees in electrical engineering from Chongqing University, Chongqing, China, in 1982, 1988, and 2000, respectively. Since 1982, he has been with the College of Electrical Engineering, Chongqing University,where he is currently a Full Professor. Between September 1998 and August 1999, he was a Visiting Professor with the University of California, Irvine. He has published more than 70 papers, is the holder of one U.S. patent and four China patents, and has three patents pending. His major research interests include the analysis and control of power electronics circuits, realization of active power filters, power factor correction techniques, and high-frequency power conversion. 